Federal Reserve Bank of Minneapolis

Research Department Staff Report 280

November 2000

\title{
Habit Persistence, Asset Returns and the Business Cycle
}

\author{
Michele Boldrin* \\ Federal Reserve Bank of Minneapolis, \\ University of Minnesota, \\ and Center for Economic Policy Research
}

\author{
Lawrence J. Christiano* \\ Northwestern University, \\ Federal Reserve Bank of Chicago, \\ and National Bureau of Economic Research
}

Jonas D. M. Fisher*

Federal Reserve Bank of Chicago

\begin{abstract}
We introduce two modifications into the standard real business cycle model: habit persistence preferences and limitations on intersectoral factor mobility. The resulting model is consistent with the observed mean equity premium, mean risk free rate and Sharpe ratio on equity. The model does roughly as well as the standard real business cycle model with respect to standard measures. On four other dimensions its business cycle implications represent a substantial improvement. It accounts for (i) persistence in output, (ii) the observation that employment across different sectors moves together over the business cycle, (iii) the evidence of 'excess sensitivity' of consumption growth to output growth, and (iv) the 'inverted leading indicator property of interest rates,' that high interest rates are negatively correlated with future output.

*First version: May 1994. Boldrin thanks the Fundación Marc Rich, Christiano thanks the National Science Foundation, and Fisher thanks the SSHRC for financial support. The views expressed herein are those of the authors and not necessarily those of the Federal Reserve Banks of Minneapolis and Chicago or the Federal Reserve System.
\end{abstract}




\section{Introduction}

General equilibrium models with complete markets and optimizing agents have enjoyed a measure of success in accounting for business cycle fluctuations in quantities. However, these models have been notoriously unsuccessful in accounting for the behavior of asset prices. ${ }^{1}$ Two failures in particular have attracted much attention: the equity premium puzzle, the fact that returns on the stock market exceed the return on Treasury bills by an average of six percentage points; and the risk-free rate puzzle, the fact that the return on Treasury bills is low on average. For the most part, the response of business cycle researchers has been to ignore the asset pricing implications of their models.

This is unfortunate. As emphasized by Cochrane and Hansen (1992), business cycle models assume that households equate intertemporal marginal rates of substitution in utility with intertemporal marginal rates of transformation. Under the complete markets hypothesis, asset returns offer a direct measure on these margins, and so should provide an excellent guide to the further development of business cycle models.

This is the perspective adopted here. ${ }^{2}$ We take the standard real business

\footnotetext{
${ }^{1}$ Influential early discussions of this include Hall (1978), Hansen and Singleton (1982, 1983), and Mehra and Prescott (1985).

${ }^{2}$ Other papers which adopt this perspective include Danthine and Donaldson (1994), Jermann
} 
cycle (RBC) model as our starting point, and modify it by replacing the power specification of utility with the habit persistence specification proposed by Constantinides (1990) and Sundaresan (1989). ${ }^{3}$ There are two reasons why we do this. First, as demonstrated by Constantinides, habit persistence has the potential to account for both of the asset return puzzles, while implying only a modest degree of risk aversion on the part of households. Alternatives (for example, Abel's 1990 "catching up with the Joneses" specification, power utility, and nonexpected utility) in practice require high-risk aversion to account for the asset pricing puzzles. ${ }^{4}$ Throughout our analysis, we restrict the parameterization of habit persistence so that the coefficient of relative risk aversion for wealth gambles averages roughly

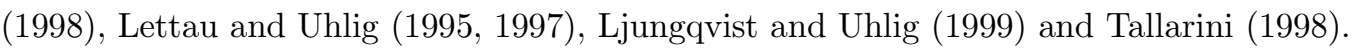

${ }^{3}$ Other researchers have investigated a different set of perturbations to the complete markets model. See, for example, Nason (1988), Reitz (1988), David, Oh, Ostroy, and Shin (1992), and Tsionas (1994). Some have followed the suggestion of Mehra and Prescott (1985) by investigating the potential of market incompleteness to account for the equity premium and risk-free rate. See, e.g., Aiyagari and Gertler (1991), Danthine, Donaldson, and Mehra (1992), Heaton and Lucas (1992, 1996), Mankiw (1986), and Weil (1992).

${ }^{4}$ The analyses we have in mind here are based on pure exchange economies in which the equilibrium consumption process is specified exogenously. The "catching-up-with-the-Joneses" and nonexpected utility specifications studied by Campbell and Cochrane (1998) and Weil (1989, 1992) use risk aversion in excess of 40, while Abel (1999) uses risk aversion in excess of 10. Risk aversion in excess of 30 is required in the Mehra and Prescott (1985) model to simultaneously drive the risk-free rate below its empirical value and the equity premium above its empirical value (see Boldrin, Christiano and Fisher 1997.) For recent evidence which suggests that levels of risk aversion this high are empirically implausible, see Barsky, Juster, Kimball, and Shapiro (1997). By resorting to nonstandard distributions for the equilibrium consumption process, it is possible to account for the asset pricing puzzles with power utility and lower risk aversion. See, for example, Kandel and Stambaugh (1991), Reitz (1988), and Tsionas (1994). 
unity. ${ }^{5}$ Our second reason for studying habit persistence preferences is that, according to several econometric analyses, this form of preferences shows promise in reconciling US data on consumption and asset returns (see Ferson and Constantinides 1991, Burnside 1994, Daniel and Marshall 1998, and Heaton 1995).

We begin by documenting that introducing habit persistence preferences into the standard real business cycle (RBC) model has no impact on the equity premium. After diagnosing the reasons for this, we address the following questions:

- What modifications to technology allow this model to account for the mean risk-free rate and equity premium?

- What are the business cycle implications of the resulting models?

With regard to the first question, we find that, in addition to habit persistence, features of technology which reduce households' ability to smooth consumption in the face of shocks are important to account for key features of asset returns. Three models which incorporate various representations of these frictions and which do well on asset returns are identified. These models are not only consistent with the mean equity premium and the mean risk free rate, they are also consistent

\footnotetext{
${ }^{5}$ For a recent discussion of the risk aversion properties of habit persistence preferences, see Boldrin, Christiano and Fisher (1997).
} 
with the observed Sharpe ratio on equity. Of the three models, two are onesector models and one is a two-sector model. We refer to this latter model as our preferred two-sector model.

We address the second question with these three models. Our preferred twosector model, as its name suggests, turns out to be the one whose business cycle implications are the best of the three. With respect to the conventional measures of business cycle volatility and comovement with output, the preferred two-sector model does roughly as well as the standard RBC model. On four other dimensions, however, our model substantially outperforms the standard model. First, the frictions in our model enhance its internal propagation of shocks, improving its ability to account for the observed persistence in output growth. Absence of internal propagation is a well-known weakness of standard RBC models (see Christiano 1988 and Cogley and Nason 1995). Second, the model accounts for the observation that employment across different sectors moves up and down together over the cycle. This is a fundamental property of business cycles that has proved surprisingly difficult to model. ${ }^{6}$ Third, our model accounts for the excess sensitivity puzzle: instrumental variable regressions indicate that consumption growth is

\footnotetext{
${ }^{6}$ For a discussion of the empirical evidence on comovement and a survey of the relevant literature, see Christiano and Fitzgerald (1998).
} 
strongly related to income, while being relatively weakly related to interest rates (Hall 1988, and Campbell and Mankiw 1989, 1991). While this puzzle is an embarrassment for the standard RBC model, it is not a problem for ours. Fourth, the model accounts for the inverted leading indicator property of interest rates: high interest rates are negatively correlated with future output. This observation is often thought to reflect the operation of monetary policy shocks. ${ }^{7}$ The fact that our model, which only has a technology shock, can account for it too suggests that the role of monetary policy shocks in the dynamics of the data may be smaller than previously thought.

The plan of the paper is as follows. Sections 2 and 3 explore the modifications needed for the one-sector and two-sector models, respectively, to account for the key asset return properties. These sections also examine the models' implications for standard business cycle statistics and measures of persistence. Because we end up analyzing a variety of model specifications, we have collected all of them together in Table 1 for convenient reference. Section 4 examines the implications of our models for employment comovement, the excess sensitivity puzzle and the inverse leading indicator phenomenon. Section 5 concludes.

\footnotetext{
${ }^{7}$ This interpretation is pursued formally in Chari, Christiano and Eichenbaum (1995). Christiano (1996) suggests that the inverted leading indicator phenomenon plays an important role in vector autoregression analyses, which in effect interpret it as reflecting the dynamic effects of shocks emanating from the monetary authority.
} 


\section{One-Sector Models}

This section explores the implications for asset returns of several versions of the one-sector model. ${ }^{8}$ We begin by focussing on one-sector models for three reasons. First, the standard RBC model is a one-sector model, and it represents an important benchmark for analysis. Second, a recent study by Jermann (1998) adopts a one-sector formulation, and reports a measure of success in accounting for asset returns. Although Jermann focuses less on business cycles than we do - he assumes hours worked are fixed - his analysis nevertheless suggests that the one-sector framework may be a promising starting point. Third, although we ultimately conclude that the one-sector framework is not the best one for understanding asset returns and business cycles simultaneously, the shortcomings of this framework provide important lessons that motivate the more successful two-sector analysis reported in the next section.

We begin by analyzing a standard RBC model. It is shown that this model does not produce an equity premium, even when habit persistence is introduced into preferences. The reason is that the flexibility of hours worked and the linearity of the capital accumulation technology offer too many opportunities to smooth

\footnotetext{
${ }^{8}$ Our definition of a one-sector model is conventional: the model's equilibrium allocations can be expressed as a function of the economy-wide aggregate stock of capital and aggregate output can be expressed as a function of aggregate capital and aggregate hours worked.
} 
consumption. ${ }^{9}$ One way to understand the implications of this for the equity premium is to note that both factors act to reduce the variability of the return on equity by reducing the variability in its capital gains component. The linearity of the capital accumulation technology in effect makes the supply of capital perfectly elastic. This by itself prevents the appearance of capital gains, since it implies that the price of capital (hence, equity) is constant. But, even inelastic capital supply and habit persistence in preferences do not guarantee an equity premium. This is because the ability to vary hours worked reduces the need to use variations in capital accumulation to smooth the response of consumption to shocks. As a result, with hours worked flexible, fluctuations in the demand for capital may be small. Without substantial fluctuation in the demand for capital, there cannot be much variation in its price.

Motivated by these observations, the second subsection below explores modifications to the one sector RBC model with habit persistence preferences. These have the effect of reducing the elasticity of capital supply and of reducing the effectiveness of labor in smoothing the response of consumption to shocks. We obtain the latter by the assumption that labor in a particular period must be

\footnotetext{
${ }^{9}$ For other discussions of the asset pricing implications of flexibility in hours worked, see Boldrin, Christiano and Fisher (1995) and Lettau and Uhlig (1995, 1997). These authors and Jermann (1998) also the discuss the implications of access to a flexible capital accumulation technology.
} 
determined prior to that period's realization of the technology shock. This can be interpreted as reflecting that variations in hours worked require advanced planning, or involve other factors that make it costly to adjust labor quickly. ${ }^{10}$ We call this the restricted labor assumption. The case where labor is permitted to respond to the current period technology shock is referred to as the unrestricted labor assumption.

We explore two mechanisms for reducing the elasticity of capital supply. ${ }^{11}$ The most straightforward of these is symmetric with the restricted labor assumption, and specifies that the investment decision must be determined prior to the realization of the current period technology shock. In this way, the quantity of installed capital is perfectly inelastic in the immediate aftermath of a shock. As with the restricted labor assumption, we interpret this as capturing the advanced planning that goes into new capital construction projects, and we refer to this as the time-to-plan assumption. ${ }^{12}$ The other mechanism is the one pursued in Jermann (1998). This posits that there are adjustment costs in converting invest-

\footnotetext{
${ }^{10}$ Examples include the considerations captured by the labor hoarding assumption in Burnside, Eichenbaum and Rebelo (1993) or the various factors emphasized in the labor search literature.

${ }^{11}$ The notion that capital supply is inelastic, at least in the short run, receives empirical support from Goolsbee (1998).

${ }^{12}$ The time-to-plan assumption for installing new capital accords well with empirical evidence on investment projects, according to Christiano and Todd (1996). In addition, the assumption has proved useful in accounting for various features of the data, including the persistence of aggregate output (see Christiano and Vigfusson (1999) and Gertler and Gilchrist (1999)).
} 
ment goods into new, installed capital. We refer to this as the adjustment cost assumption.

We show that either of these mechanisms, as long as they are coupled with the restricted labor assumption, can account for the features of asset returns that we study. Because these specifications receive special emphasis in our analysis, we refer to them by abbreviated names. The time-to-plan model refers to the onesector model incorporating the time-to-plan and restricted labor assumptions. The adjustment cost model is defined analogously. Although these two models have similar asset pricing implications, their implications for business cycles are different. The business cycle implications of the time-to-plan model are modestly worse than those of the standard RBC model, while those of the adjustment cost model are substantially so. The lessons we infer from these findings are summarized at the end of this section.

\subsection{A Standard Real Business Cycle Model}

\subsubsection{The Model}

We analyze a version of the Hansen (1985) and Rogerson (1988) model studied in Christiano and Eichenbaum (1992), in which the time period is three months. The preferences of the representative agent are as follows: 


$$
E_{0} \sum_{t=0}^{\infty} \beta^{t}\left[\log \left(C_{t}-b C_{t-1}\right)-H_{t}\right], 0<\beta<1, b \geq 0
$$

where $0 \leq H_{t}$ denotes time $t$ labor, $C_{t} \geq 0$ denotes consumption, and $E_{0}$ is the conditional expectation operator. ${ }^{13}$ When $b>0$ household preferences are characterized by habit persistence. ${ }^{14}$ When $b=0$, these preferences correspond to those in a standard RBC model. ${ }^{15}$

The technology is specified as follows. Given a beginning of period $t$ stock of capital, $K_{t}$, state of technology, $Z_{t}$, and a quantity of labor, $H_{t}$, output, $Y_{t}$, is determined according to:

$$
Y_{t}=K_{t}^{\alpha}\left(Z_{t} H_{t}\right)^{1-\alpha}, 0<\alpha<1
$$

\footnotetext{
${ }^{13}$ In this paper we work with what Hansen (1985) calls the 'indivisible labor' model. The results are moderately sensitive to whether we work with this or with the 'divisible labor model'. In this formulation the utility function, $(2.1)$, is replaced by the expected present discounted value of $\log \left(C_{t}-b C_{t-1}\right)+\varsigma \log \left(1-H_{t}\right)$, with $\varsigma$ chosen to ensure that hours worked along a steady state growth path is 0.30 . We indicate which results are sensitive to the specification of utility in footnotes below.

${ }^{14}$ The term, $b C_{t-1}$, is sometimes referred to as the household's habit stock. We have explored more general specifications in which the habit stock is also a function of consumption in earlier periods, and have found that this has little impact on asset prices. Also, Christiano and Fisher (1998) explain why a model's business cycle implications are improved by adopting the simpler formulation in (2.1). These are the reasons why we adopt it here.

${ }^{15}$ Our (standard) specification of the habit persistence utility function has the distinctive feature that the present discounted value of the utility of a consumption sequence is nonmonotone in the consumption of any particular period. This reflects the fact that, although the period utility function is increasing in current consumption, next period's utility is decreasing in current consumption. This latter effect dominates at high values of consumption. In the simulations computed for this paper, consumption is always in the region of positive marginal utility.
} 
The state of technology evolves according to:

$$
Z_{t}=\exp \left(x_{t}\right) Z_{t-1}, \quad x_{t} \sim N\left(\bar{x}, \sigma^{2}\right), \quad \forall t \geq 0 .
$$

The resource constraint is:

$$
C_{t}+I_{t} \leq Y_{t}
$$

where $I_{t}$ denotes investment. Finally, the technology for accumulating capital is:

$$
K_{t+1}=(1-\delta) K_{t}+I_{t}, 0 \leq \delta \leq 1 .
$$

Here, and throughout the analysis, we exploit the second welfare theorem and find the equilibrium allocations by solving the relevant planning problem. The planning problem for this model is: maximize (2.1) subject to (2.2)-(2.5) and $C_{-1}$, $K_{0}$ given. In this, and all other models considered in the paper, we approximate the quantities that solve the planning problem using non-linear functions of the state computed using the methods described in Judd (1998) and Christiano and Fisher (2000).

It is well understood how to decentralize the allocations that solve the planner's problem by means of competitive markets, and so we do not discuss the details 
here. ${ }^{16}$ Prices and rates of return are derived from the solution to the planning problem as follows. The rate of return on a risk-free asset is

$$
r_{t}^{f}=\frac{\Lambda_{c, t}}{E_{t} \Lambda_{c, t+1}}-1,
$$

where $\Lambda_{c, t}$ is the Lagrange multiplier on the resource constraint, (2.4), in the planner's problem. This multiplier is the derivative of expected present discounted utility with respect to $C_{t}$. The rate of return on equity is

$$
r_{t+1}^{e}=\frac{\alpha\left(\frac{Z_{t+1} H_{t+1}}{K_{t+1}}\right)^{1-\alpha}+P_{k, t+1}}{P_{k^{\prime}, t}}-1 .
$$

Here, $P_{k^{\prime}, t}$ denotes the consumption good value of a newly installed unit of capital, to be used in production at the beginning of period $t+1$. Also, $P_{k, t+1}$ is the value of that same unit of capital at the end of period $t+1$. We refer to $P_{k^{\prime}, t}$ as the date $t$ price of equity and to the expression, $P_{k, t+1} / P_{k^{\prime}, t}$, as the capital gain. ${ }^{17}$ The time subscript convention used in $r_{t}^{f}$ and $r_{t+1}^{e}$ identifies the date on which the relevant

\footnotetext{
${ }^{16}$ For a decentralization with one period-lived firms, see Boldrin, Christiano and Fisher (1995). For an alternative decentralization based on infinite-lived firms, see Jermann (1998).

${ }^{17}$ For an extended discussion of (2.7) in an explicit market setting, see Boldrin, Christiano and Fisher (1997) and Christiano and Fisher (1998, technical appendix). Expression (2.7) assumes that, in the underlying market economy, capital accumulation is 100 percent equity financed. In section 3.2 below, we explain why this counterfactual assumption does not distort our analysis.
} 
payoff becomes known. In both cases, the date of the payoff is period $t+1$. The mean equity premium is $E\left(r_{t+1}^{e}-r_{t}^{f}\right)$.

Our specification of the resource constraint, (2.4), and the capital accumulation equation, (2.5), imply $P_{k^{\prime}, t}=1, P_{k, t+1}=1-\delta$. Evidently, in this model there is no variation in the capital gain component of the return to equity. ${ }^{18}$

\subsubsection{Parameterizing the Model}

We used the following non-habit parameter values: $\beta=0.99999, \alpha=0.36, \delta=$ $0.021, \bar{x}=0.0040$ and $\sigma=0.018$. The indicated value for the discount factor was chosen to maximize the model's ability to account for the risk free rate. For the empirical rationale underlying the other parameter values, see Christiano and Eichenbaum (1992).

Our method for choosing a value for $b$ optimizes the model's ability to account for the mean equity premium and the mean risk free rate. The metric we used for this is $\mathcal{L}(b)$, where

$$
\mathcal{L}(b)=\left[\hat{\nu}_{T}-f(b)\right] \hat{V}_{T}^{-1}\left[\hat{\nu}_{T}-f(b)\right]^{\prime}
$$

\footnotetext{
${ }^{18}$ As emphasized in Sargent (1980), there would be variation in the capital gains term if there were an occasionally binding non-negativity constraint on gross investment.
} 
Here, $\hat{\nu}_{T}$ is the $2 \times 1$ vector composed of the sample average of the annual observations on the risk-free rate and the equity premium reported in Cecchetti, Lam, and Mark (1993) (CLM). The $2 \times 2$ matrix $\hat{V}_{T}$ is CLM's estimate of the underlying sampling variance. Finally, $f(b)$ is the model's implied average annual risk-free rate and equity premium, conditional on $b$ and the other parameter values. ${ }^{19}$ We considered $b \in[0,0.9]$ subject to the requirement that $C_{t} \leq b C_{t-1}$ and $\Lambda_{c, t} \leq 0$ are never observed in the Monte Carlo simulations used to evaluate $f$. Let

$$
J=\mathcal{L}\left(\hat{b}_{T}\right)
$$

where $\hat{b}_{T}$ minimizes $\mathcal{L}(b)$. Under the null hypothesis that the model is true, and ignoring sampling uncertainty in the other parameters, $J$ has a Chi-square distribution with 1 degree of freedom. Since $J$ is in practice either very small or very large, we do not report its value or its $p$-value in the analysis below.

\subsubsection{No Equity Premium in the RBC Model, and Why}

We find that there is no value of $b$ which makes $f(b)$ close to $\hat{\nu}_{T}$ in the sense of driving $\mathcal{L}(b)$ below the 10 percent critical value of the Chi-square distribution with

\footnotetext{
${ }^{19} \mathrm{An}$ annual return for a given year is computed as the sum of the rate of return over each quarter in that year. The mapping, $f$, was executed by computing the average of the mean risk free rate and mean equity premium across 500 artificial data sets, each of length 200 quarters.
} 
1 degree of freedom. Although the calibration procedure drives $b$ to the corner, $\hat{b}_{T}=0.9, b$ has essentially no impact on $\mathcal{L}$. This can be seen by considering the results in Table 2. The first column exhibits results based on US data, while the second and third columns display the model's implications for $b=0$ and $b=0.9$, respectively. Note that both the average equity premium and the average risk free rate are basically invariant to $b$, and the equity premium remains essentially at zero.

Why is the equity premium in this economy so low? The question is interesting in part because the results are so strikingly different from those obtained for the endowment economy in Boldrin, Christiano and Fisher (1997) (BCF). They parameterized the utility function using essentially the same metric, (2.8), and obtained a low risk free rate and a substantial equity premium by raising $b$.

To gain insight into why the equity premium in the production economy is so low, we use the following expression:

$$
E\left(r_{t+1}^{e}-r_{t}^{f}\right)=S \sigma_{r e}, S=-\rho s
$$

Here, $s=\sigma_{m} / E m_{t+1}, m_{t+1}$ corresponds to the marginal rate of substitution in consumption from period $t$ to period $t+1$, and $E u, \sigma_{u}$ denote the mean and vari- 
ance, respectively, of $u$. Also, $\rho$ denotes the correlation between $r_{t+1}^{e}-r_{t}^{f}$ and $m_{t+1}$. Finally, $S$, which can be computed from $E\left(r_{t+1}^{e}-r_{t}^{f}\right) / \sigma_{r e}$, is the Sharpe ratio for equity. ${ }^{20}$ Expression (2.10) manipulates the well known efficiency condition, $E_{t}\left(r_{t+1}^{e}-r_{t}^{f}\right) m_{t+1}=0$. It indicates that the failure of the equity premium to increase significantly with $b$ can be understood in terms of $S$ and $\sigma_{r^{e}}$. According to the evidence in Table 2, both these variables are low and relatively insensitive to $b$. We now discuss modifications to the model that can increase $S$ and $\sigma_{r^{e}}$.

To appreciate the changes needed to increase $\sigma_{r e}$, it is helpful to understand why this variable is so small in the production economy with habit persistence. The reason is that, as noted above, there is no variation in the capital gains component of the rate of return on equity, (2.7). The underlying economics of this result is that the supply curve of capital is perfectly elastic in the model. This is why the price of capital is always constant and there cannot be any variation in capital gains. As a result, variation in the return to equity is driven entirely by variation in the marginal product of capital, which is known to be quite small in standard models. ${ }^{21}$

\footnotetext{
${ }^{20}$ This definition of the Sharpe ratio associated with any particular asset is standard in the literature (see, e.g., Campbell, Lo and MacKinlay (1997, p. 188).) A related concept is the largest Sharpe ratio over all possible assets. In our context, this is $s$, since the largest possible value of $-\rho$ is 1 . For a recent discussion of the usefulness of this concept, see Lettau and Uhlig (1997).

${ }^{21}$ See, for example, Christiano (1987).
} 
This suggests that to increase $\sigma_{r}$ it is important to introduce factors which make the supply of capital inelastic. But, inelastic capital per se is not sufficient to raise $\sigma_{r e}$ significantly. For example, in an endowment economy the productive capital (a Lucas 'tree') is in fixed supply, and so it is completely inelastic. Mehra and Prescott (1985) show that, despite this, this model does not generate a significant equity premium. BCF show that when habit persistence preferences are introduced into that model, the demand for capital shifts around in the right way so that $\sigma_{r e}$ is large and there is a substantial equity premium. This suggests that to raise $\sigma_{r^{e}}$ one needs not just that (i) the supply of capital is inelastic, but also that (ii) the demand for capital varies appropriately.

Intuition appears to be a less reliable guide regarding ways of increasing $S .{ }^{22}$ However, our computational experiments, reported below, indicate that the factors that we use to capture (i) and (ii) also help increase the Sharpe ratio.

\footnotetext{
${ }^{22}$ Following is a brief explanation. We focus on $s$, since in practice we find that $\rho$ is relatively unresponsive to model changes. First, consider an increase in $b$ when the technology is as it is in the standard RBC model. Holding the consumption allocations fixed, we can expect this to produce an increase in $\sigma_{m}$. At the same time, the increase in $b$ has the effect of making consumption smoother in equilibrium, both because the incentive to do so is enhanced and because it is feasible under the RBC technology. This has the opposite impact on $\sigma_{m}$, driving it down. Thus, the net impact of $b$ on $\sigma_{m}$, hence $s$, is ambiguous in this case. Second, suppose that there is a technology in place which makes it difficult to smooth the response of consumption to shocks. In this case, we might expect an increase in $b$ to raise $\sigma_{m}$. However, by enhancing the precautionary saving motive, we can also expect the increase in $b$ to lead to a fall in the risk free rate, i.e., a rise in $E m_{t+1}$. But, with an increase in $b$ producing a rise in both the numerator and denominator of $s$, the impact on $s$ itself is ambiguous.
} 
The preceding considerations indicate that one reason the equity premium in the standard RBC model is so low is that it fails to incorporate (i). As it turns out, another reason is that the flexibility of hours worked undermines (ii). This will be shown in the computational results below. In contrast, the reason $\mathrm{BCF}$ has no difficulty producing an equity premium is that the endowment economy

trivially satisfies (i) and it does not have flexible hours worked to undermine (ii).

The intuition guiding our effort to identify model features that improve its implications for the equity premium focuses on raising $\sigma_{r e}$. Of course, a success would not be very interesting if it required going to a specification which implied a counterfactual value of $\sigma_{r e}$. As a result, when we evaluate a model, we also take into account its implications for the Sharpe ratio, $S$.

\subsection{Modifications to the One Sector Model}

This subsection explores various modifications to the one sector model which are designed to improve its asset pricing implications. The first subsection explores the time-to-plan assumption and the second considers the adjustment cost assumption. 


\subsubsection{Time-to-Plan Assumption}

As noted above, the time-to-plan assumption requires that date $t$ investment be chosen before the date $t$ technology shock is realized. This necessitates the following change in the formulas for $P_{k^{\prime}, t}$ and $P_{k, t+1}$ :

$$
P_{k^{\prime}, t}=\frac{\Lambda_{k^{\prime}, t}}{\Lambda_{c, t}}, P_{k, t+1}=(1-\delta) \frac{\Lambda_{k^{\prime}, t+1}}{\Lambda_{c, t+1}},
$$

where $\Lambda_{k^{\prime}, t}$ is the Lagrange multiplier on (2.5) in the planner's problem. In the standard RBC model, $\Lambda_{k^{\prime}, t}=\Lambda_{c, t}$ always. This equality does not hold under the time-to-plan assumption since it only requires $E_{t-1} \Lambda_{k^{\prime}, t}=E_{t-1} \Lambda_{c, t}$. We consider two versions of the model which incorporates the time-to-plan assumption, one which also implements the restricted labor assumption (i.e., the time-to-plan model) and another which does not.

Note that the parameters in each of these models coincide with the ones in the model of the previous section. In each case, we assigned values to them using the method in section 2.1.2. Interestingly, in the unrestricted labor case, the estimated value of $b$ is at its upper bound, while in the restricted labor case, it is much lower, at 0.66 . The reason for this difference is instructive about the properties of the models. Recall the intuition described above, according to which 
obtaining a high equity premium requires raising $\sigma_{r^{e}}$ by increasing the volatility of the price of capital. The time-to-plan assumption on investment contributes to this by making capital supply perfectly inelastic. The restricted labor assumption and habit persistence together work to produce the right cyclical variation in the demand for capital (condition (ii) in section 2.1.3). When hours worked is perfectly flexible (the unrestricted labor case) then the burden for producing the right cyclical variation in the demand for capital falls more heavily on habit persistence. This is why it is that in the unrestricted labor case $b$ is high, while it is much lower in the restricted labor case.

We now turn to the financial implications of the model with unrestricted labor. In Table 2 we see that simply adding the time-to-plan assumption to the RBC model with habit persistence generates only a small rise in $\sigma_{r e}$ and in the Sharpe ratio (see the column marked 'Unrestricted Labor, Time-to-plan'). As a result, there is still practically no equity premium. However, consistent with the intuition developed earlier, when we also impose the assumption that hours worked are decided prior to the technology shock ('Restricted labor, Time-to-plan'), the asset pricing implications are improved substantially. Now the equity premium coincides with its empirical estimate, while the mean risk free rate is only a few basis points too high. Notably, the Sharpe ratio essentially coincides with its em- 
pirical value. All this is achieved despite a reduction in $b$ to $b=0.66$. This model (i.e., the time-to-plan model) also does tolerably well on the correlation of equity prices with output and the volatility of equity prices.

An important shortcoming of the time-to-plan model is that it overstates the volatility of the risk free rate substantially, by a factor of almost 5 . This is a shortcoming of all the models we consider which succeed on the mean risk free rate, the mean equity premium and the Sharpe ratio. As a result, we delay discussion of this issue until we have presented all of our results.

Given the relative success of the time-to-plan model on financial market implications, it is worth investigating its business cycle implications. These are displayed in Table 3. We evaluate the model's performance by comparing it to the performance of the standard RBC model ('RBC, $b=0$ '). Consider the standard business cycle statistics in Panel A first. Apart from the relative volatility of consumption and investment, the model does as well or better than the standard RBC model. A dimension on which it does somewhat better, is on the relative volatility of hours worked. However, the model's performance on the relative volatility of consumption and investment is poor. It substantially overstates the relative volatility of consumption and it understates the relative volatility of investment. We view these as significant shortcomings of the time-to-plan model 
and they lead us to conclude that it does less well on standard business cycle statistics than the standard RBC model.

Persistence is also considered an important feature of business cycles. Therefore, we now consider the implications of the time-to-plan model for the autocorrelation of output and consumption growth, in Table 3, Panel B. The model represents a significant improvement over the standard RBC model on this dimension. The model's output persistence even overstates what we see in the data. By comparing the results in the 'RBC, $b=0$ ', 'Restricted Labor, Time-to-plan' and 'Unrestricted Labor, Time-to-plan' columns, we see that the key factor underlying this persistence result is the restricted labor assumption. This can be seen in Figure 1 as well. This displays the response in the time-to-plan model of $Y, C$, $I$, and $H$ to a positive, one-standard deviation shock to technology, $x_{t}$, in period 0 (the response of two other models is displayed there too, but this is discussed later.) The strong, positive autocorrelation in output is in part due to the delay in the response of hours worked. This has the effect of making the period 1 response of output substantially larger than the period 0 response.

Turning to the autocorrelation of consumption growth, we see that the model takes a step in the wrong direction, by comparison with the standard RBC model. To see why this happens, consider Figure 1, which shows how consumption surges 
in the period of the shock. This response is of course inevitable, given that investment and hours worked cannot respond. In the period after the shock, when these variables can respond, then consumption drops somewhat. This hooked response of consumption is the reason for its negative autocorrelation.

According to the autocorrelations alone, the evidence on the relative performance of the time-to-plan model is mixed. For this reason, we conclude that when both the standard business cycle statistics and persistence are considered, the time-to-plan model represents a modest step in the wrong direction relative to the standard RBC model. Of course, it represents a dramatic step forward for asset pricing.

\subsubsection{Adjustment Cost Assumption}

The adjustment cost assumption replaces the capital accumulation technology, (2.5), with the specification used in Jermann (1998):

$$
K_{t+1}=(1-\delta) K_{t}+\phi\left(I_{t} / K_{t}\right) K_{t},
$$

where 


$$
\phi\left(I_{t} / K_{t}\right)=\frac{a_{1}}{1-1 / \xi}\left(\frac{I_{t}}{K_{t}}\right)^{1-1 / \xi}+a_{2}
$$

and $a_{1}, a_{2}$ are chosen so that the balanced growth path is invariant to $\xi .{ }^{23}$ It is easily verified that when $\xi=\infty$, this formulation reduces to (2.5). Prices of capital are now given by:

$$
P_{k^{\prime}, t}=\frac{1}{\phi^{\prime}\left(\frac{I_{t}}{K_{t}}\right)}, P_{k, t+1}=\left[(1-\delta)+\phi\left(\frac{I_{t+1}}{K_{t+1}}\right)-\phi^{\prime}\left(\frac{I_{t+1}}{K_{t+1}}\right) \frac{I_{t+1}}{K_{t+1}}\right] P_{k^{\prime}, t+1} .
$$

The parameter $\xi$ is the elasticity of investment, $I_{t}$, with respect to Tobin's $q .{ }^{24}$ As in the time-to-plan case, we consider two models that incorporate the adjustment cost assumption. One also adopts the restricted labor assumption (i.e., the adjustment cost model) and the other does not.

\footnotetext{
${ }^{23}$ The formulas are:

$$
a_{1}=(\exp (\bar{x})-1+\delta)^{1 / \xi}, a_{2}=\frac{1}{\xi-1}(1-\delta-\exp (\bar{x}))
$$

${ }^{24}$ Tobin's $q$ is the ratio $P_{k^{\prime}, t}$ to the price of investment goods, which is unity here. It is easily verified from the fact, $P_{k^{\prime}, t}=1 / \phi^{\prime}\left(I_{t} / K_{t}\right)$, that

$$
\frac{\partial \ln I_{t}}{\partial \ln q_{t}}=\xi
$$
}


The results in Tables 2 and 3 are based on setting $\xi=0.23$. We chose this value for two reasons. First, it facilitates comparing our results with Jermann (1998), who also uses it. Second, this value is near the lower bound of the range of estimates reported in the empirical literature on Tobin's $q$ (see Christiano and Fisher (1998).) As a result, the chosen value for $\xi$ minimizes the supply elasticity of capital - hence, maximizes the models' ability to account for asset returns while still lying in the range of empirical plausibility.

Conditional on this value for $\xi$, we assigned values to the other parameters using the method in section 2.1.2. Whether or not we impose the restricted labor assumption, the estimated value of $b$ is at its upper bound. Our interpretation of this is that the adjustment cost formulation, by allowing some elasticity in capital supply, places a relatively heavy burden on cyclical fluctuations in the demand for capital for producing the right amount of variation in the price of capital. The role of the high value of $b$ is to generate this variation. ${ }^{25}$

The results in Table 2 indicate that, as we found in the previous subsection, without the restricted labor assumption the model generates only a very small

\footnotetext{
${ }^{25}$ Jermann (1998) also reports a high value of $b$. His value, 0.83 , is somewhat lower than ours for two reasons: he has higher curvature in utility and he assumes hours worked is constant. The latter reduces the burden on habit persistence for creating cyclical fluctuations in the demand for capital. The high curvature reduces the burden on $b$ specifically for producing these fluctuations in the demand for capital.
} 
equity premium. But, when the restricted labor assumption is imposed, then a substantial equity premium occurs. Note that this model understates the equity premium by a little over 2 percentage points. The discrepancy is not very important, however, because the gap can be closed by a modest increase in curvature on utility above the logarithm. ${ }^{26}$ Overall, we find that the adjustment cost model does roughly as well on asset prices as the time-to-plan model.

We now turn to the business cycle implications of the adjustment cost model, which are reported in Table 3. Consider first the standard business cycle statistics, displayed in Panel A. A severe shortcoming of the model is its implication that labor is countercyclical. ${ }^{27}$ This counterfactual property is a consequence of the fact that the adjustment cost on capital acts as a tax on the proceeds of labor. Hours worked fall after a technology shock because this tax causes the resulting

\footnotetext{
${ }^{26}$ This assessment is based on a particular computational experiment. We adopted the following specification of period utility, designed to increase curvature on consumption while maintaining the balanced growth property of our model:

$$
\left[\left(C_{t}-b C_{t-1}\right)\left(1-H_{t}\right)^{\eta}\right]^{1-\sigma} /(1-\sigma) .
$$

We found that with $\sigma=3, \eta=2.18, b=0.834$ and $\beta=0.99616$, the model exactly reproduces the empirical estimate of the equity premium and the risk free rate. Here, $\eta$ was chosen to guarantee that the steady state value of $H_{t}$ is 0.3 . The values for $\beta, b$, and $\sigma$ were obtained as follows. For each of the following values of $\sigma, \sigma=1,2,3$, we searched for values of $\beta$ and $b$ that minimize the citerion, (2.9). The only value of $\sigma$ which resulted in the criterion being zero was $\sigma=3$. The reason $\beta$ had to be reduced a little relative to what it is in the text, is that with the larger value of $\sigma$, the risk free rate would otherwise have been too low.

${ }^{27}$ This is not sensitive to the indivisible labor assumption in the utility function, (2.1). We found that the divisible labor version of the model (see footnote 13) has the same implication.
} 
income effect to dominate the substitution effect. The problem is intensified when curvature in preferences is raised in the way discussed in the previous paragraph. ${ }^{28}$ In contrast with the time-to-plan model, where the difficulties in adjusting investment only extend for one period, in the adjustment cost model they last for many periods. This is why the drop in hours worked in response to a positive technology shock is also persistent over time (see Figure 1). Another difficulty with the model is that it substantially understates the volatility of output. This is also a consequence of the nature of the hours worked response to a technology shock.

Now consider the persistence properties of the model, reported in Table 3, Panel B. There we see that output growth is strongly negatively autocorrelated. This is another consequence of the nature of the hours worked response to a technology shock. The fact that hours worked cannot respond in the period of the shock implies that output surges then (see Figure 1). However, the fact that hours worked drops in the following period implies that output drops then too. This hooked response of output to a shock is the reason that output growth is negatively autocorrelated. Interestingly, consumption growth is far too positively

\footnotetext{
${ }^{28}$ We experimented with alternative parameter values and could not find a configuration that would both preserve the model's good asset pricing implications and make hours worked procylical at the same time. For example, we tried higher values of $\xi$, which, other things the same, make employment less countercyclical. However, this change also reduces the model's equity premium. When we raised curvature on utility to restore the good asset pricing performance, we found that the change again exacerbated the countercyclicality of hours worked.
} 
autocorrelated relative to the data. The reason this autocorrelation is so much greater than in the time-to-plan model is that here the technology does not require that consumption surge in the period of a shock.

We conclude that when the standard business cycle statistics and measures of persistence are considered, the adjustment cost model represents a substantial step in the wrong direction by comparison with the standard RBC model. ${ }^{29}$ The root of the problem with the adjustment cost model lies in the persistently negative response of hours worked to a positive technology shock. ${ }^{30}$ This in turn reflects the persistence of the friction introduced with the adjustment cost formulation.

\subsection{Lessons From the One Sector Analysis}

The analysis in this section explored several modifications that are helpful in improving the asset pricing implications of the standard RBC model, without reducing its business cycle performance. These include: (i) habit persistence in

\footnotetext{
${ }^{29}$ It is important to emphasize that our results only warrant rejecting the notion that adjustment costs play a fundamental role in accounting for the equity premium. We agree with the Tobin's $q$ literature, which views adjustment costs as crucial for understanding the fluctuations in Tobin's $q$. However, the curvature in the adjustment cost function needed for this is small, far too small to have a material impact on equity premium or to produce countercyclical fluctuations in employment. For an elaboration on these observations, see Christiano and Fisher (1998).

${ }^{30}$ The findings with respect to the adjustment cost model are consistent with the results reported in Jermann (1998). As noted above, Jermann (1998) studies a version of this model in which hours worked are constant, and this is why the business cycle implications for this variable are not apparent from his work.
} 
preferences, (ii) features of technology that hamper the ability to use variations in hours worked to smooth consumption, and (iii) features which reduce the elasticity of capital supply. Regarding (iii), we found that the modifications work best if their effects are transient. Adjustment costs, whose effects persist through time, did not work well.

We achieved the best resuls when we incorporated (i)-(iii) into a one-sector model using the time-to-plan assumption. However, though the asset price implications were dramatically improved, the volatility of consumption was counterfactually large. We infer that the time-to-plan assumption is too blunt as a device for rendering capital supply inelastic. The next section identifies a device which corrects this problem.

\section{Two-Sector Economies}

Our interpretation of the absence of an equity premium in the standard RBC model with habit persistence is that it reflects two related features of that model: (i) the infinite supply elasticity of capital, and (ii) the ability to use variations in hours worked to smooth the consumption response to shocks. The previous section explored the most natural (to us) ways of correcting these problems in the one sector model. We found that, although the resulting models can replicate 
the observed equity premium, risk free rate and Sharpe ratio, their business cycle implications are not as good as those of the RBC model.

Motivated by the lessons from these results, this section pursues a different, and ultimately more successful, set of modifications to the standard RBC model. This is the preferred two-sector model discussed in the introduction to the paper. In the construction of this model, we continue to adopt the habit persistence assumption in preferences, as specified in (2.1). However, we pursue a somewhat different strategy for addressing (i) and (ii). We assume that consumption and investment are nonhomogeneous goods produced in separate sectors, each with the same production technology, (2.2)-(2.3). In addition, we assume that the capital and labor used in each sector must be committed before the realization of the current period shock. The notion that labor and capital cannot be instantaneously reallocated between sectors has been well documented. For example, the search literature documents the various factors that inhibit the intersectoral movements of labor (see, for example, Phelan and Trejos (1996) and the papers they cite). A recent paper by Ramey and Shapiro (1998) documents the difficulties of reallocating capital across sectors.

Our preferred two-sector model is closely related to the time-to-plan model. The easiest way to see the relationship between the two is to consider the two- 
sector interpretation of the time-to-plan model. ${ }^{31}$ Under this interpretation, that economy is actually a two-sector economy in which identical production functions are used to produce consumption and investment goods, and capital and labor resources are freely mobile between sectors after the realization of the technology shock. The restricted labor assumption requires that aggregate labor be determined before the realization of the technology shock, but allows the sectoral allocation of that labor to be determined afterward. In addition to the restricted labor assumption, the preferred two-sector model also imposes the immobile labor assumption, which prevents labor from being reallocated between sectors after a shock. We refer to the case in which the sectoral allocation of labor can adjust to a technology shock as the mobile labor assumption.

A drawback of the time-to-plan model is that it overstates the volatility of consumption. The assumption that investment is decided prior to the realization of the technology shock implies that consumption must absorb the full amount of a change in output caused by a shock to technology. In effect this requires that, when there is a positive shock to technology, capital and labor resources are allocated away from the investment sector and towards consumption. In the

\footnotetext{
${ }^{31}$ For a discussion of the two-sector interpretation of the standard RBC model, see Benhabib, Rogerson and Wright (1991).
} 
preferred two-sector model, these sectoral reallocations are not permitted. As a result, the consumption response to a technology shock is smaller. This is why the implications for the volatility of consumption of the preferred two-sector model turn out to be superior to those of the time-to-plan model.

This section is divided into two parts. In the first, we present the preferred two-sector model and its implications for asset returns, standard business statistics and persistence. We show that the asset pricing implications of this model are as good as those of the time-to-plan model. In addition, the preferred two-sector model corrects the time-to-plan model's shortcomings with respect to business cycle statistics. We also document the role played by habit persistence and the restrictions on labor in these results.

The second part considers leverage. Throughout most of our analysis we assume that, in the underlying market decentralization, capital is 100 percent equity financed. Here, we consider the impact on our analysis of the assumption that debt is also used. We suppose that the debt to equity ratio corresponds roughly to its average value in the data. We show that nothing essential in our results hinges on leverage. 


\subsection{The Preferred Two-Sector Model}

The equilibrium quantity allocations maximize (2.1), with $H_{t} \equiv H_{c, t}+H_{i, t}$, subject to:

$$
\begin{gathered}
K_{c, t}^{\alpha}\left(Z_{t} H_{c, t}\right)^{1-\alpha} \geq C_{t}, \\
K_{i, t}^{\alpha}\left(Z_{t} H_{i, t}\right)^{1-\alpha}+(1-\delta)\left(K_{c, t}+K_{i, t}\right) \geq K_{c, t+1}+K_{i, t+1}, \\
H_{c, t}, H_{i, t} \geq 0 \text { and } C_{-1}, K_{c, 0}, K_{i, 0}>0 \text { given. }
\end{gathered}
$$

Here the subscripts $c$ and $i$ denote the consumption and investment good sectors, respectively. As before, we require that the sum $K_{c, t+1}+K_{i, t+1}$ be chosen as a function of the date $t$ state of nature. However, we now also require that the individual terms $K_{c, t+1}$ and $K_{i, t+1}$ be chosen as a function of the date $t$ state of nature. Sectoral hours worked, $H_{i t}$ and $H_{c t}$, are also determined prior to the realization of the current period technology shock. Thus, not only do we restrict aggregate employment, $H_{t}$, to be determined in advance, but we also rule out reallocation of labor between sectors after the shock. Finally, we assume that $Z_{t}$ evolves according to (2.3).

In this model, the rates of return on equity in the two sectors differ from each other, and so we need a notation that reflects this. The rate of return on equity 
in the consumption sector is given by

$$
r_{c, t+1}^{e}=\frac{\alpha\left[\frac{Z_{t+1} H_{c, t+1}}{K_{c, t+1}}\right]^{1-\alpha}+P_{k, t+1}}{P_{k^{\prime}, t}}-1
$$

while the rate of return on equity in the investment good sector is given by

$$
r_{i, t+1}^{e}=\frac{P_{k^{\prime}, t+1} \alpha\left[\frac{Z_{t+1} H_{i, t+1}}{K_{i, t+1}}\right]^{1-\alpha}+P_{k, t+1}}{P_{k^{\prime}, t}}-1 .
$$

Here,

$$
P_{k^{\prime}, t}=\frac{\Lambda_{i, t}}{\Lambda_{c, t}} \text { and } P_{k, t}=(1-\delta) P_{k^{\prime}, t}
$$

where $\Lambda_{c, t}$ and $\Lambda_{i, t}$ denote the Lagrange multipliers on (3.1) and (3.2) in the planner's problem. We define the aggregate rate of return on equity, $r_{t+1}^{e}$, in the following way:

$$
r_{t+1}^{e}=\frac{K_{c, t+1}}{K_{t+1}} r_{c, t+1}^{e}+\frac{K_{i, t+1}}{K_{t+1}} r_{i, t+1}^{e}
$$

where $K_{t+1}=K_{c, t+1}+K_{i, t+1}$. Also, the risk-free rate of return, $r_{t}^{f}$, is computed using (2.6), with the understanding that $\Lambda_{c, t}$ is now the multiplier on (3.1).

The parameters in this model coincide with those in the one sector model with habit persistence, and we assign values to them using the method in section 2.1.2. Note from Table 4 that the estimated value of $b$ is 0.73 , somewhat larger than the 
value reported for the time-to-plan model (see Table 2). The intuition underlying this difference is straightforward. In the time-to-plan model the supply of new capital is inelastic and fixed. In the two-sector model, the supply is still perfectly inelastic. However, now that supply shifts right with a positive technology shock, and left with a negative one. This places a greater burden on fluctuations in the demand for capital for producing the right variation in its equilibrium price. The higher value of $b$ allows habit persistence to take up this greater burden.

The asset pricing implications of this model are reported in Table 4 ('Preferred two-sector model'). Note that these are essentially identical to those implied by the time-to-plan model (see Table 2). Significantly, the model almost exactly replicates the mean risk free rate, mean equity premium, and the Sharpe ratio. As in the time-to-plan model, the preferred model's primary failing is that it overstates the volatility of the risk free rate.

The results in Table 4 document the key role played by labor inflexibilities and habit persistence in the model's asset pricing performance. First, note that whenever $b=0$, the equity premium and Sharpe ratio are essentially zero. Second, the table shows what happens when we maintain the assumption that aggregate labor, $H_{t}$, is determined prior to the realization of the period $t$ shock, but labor can be freely reallocated between sectors, subject to the constraint on the aggre- 
gate ('Mobile labor, Restricted labor'). Note that in this case there is no equity premium, even when $b$ is set to its upper bound. With labor able to freely shift between sectors, hours worked is simply too effective at facilitating consumption smoothing in response to shocks. This virtually eliminates the cyclical shifts in the demand for capital that are needed to produce variation in the price of capital. The result is that the variability in that price is very low and that $\sigma_{r e}$ is small too. When labor is completely flexible ('Mobile labor, Unrestricted labor') the results are fundamentally very similar to what they are in the mobile, restricted case. This model confirms our previous findings that inflexibilities in labor are a crucial ingredient for producing an equity premium.

Now consider the business cycle implications of the model, reported in Table 5. With one exception, the performance on standard business cycle statistics, reported in Panel A, is similar to that of the time-to-plan model. The exception is that the relative volatility of consumption is now considerably smaller, though it does still overstate the corresponding empirical magnitude somewhat. ${ }^{32}$ Panel B displays the persistence properties of the model. The results indicate that the preferred model represents a modest improvement over the time-to-plan model.

\footnotetext{
${ }^{32}$ This is a place where our indivisible labor assumption on utility matters. When we adopt the divisible labor formulation, we find that $\sigma_{C} / \sigma_{Y}=0.78$.
} 
In particular, the autocorrelation of consumption growth is close to zero for the preferred model, while it is -0.14 in the time-to-plan model. The reason for the improved performance on consumption growth can be seen in Figure 1. This shows that there is a smaller surge in consumption after a positive technology shock than in the time-to-plan model. Otherwise, the impulse response functions for the preferred two-sector model and the time-to-plan model look quite similar. We conclude that, based on standard business cycle statistics and persistence, our preferred two-sector model represents an improvement over the time-to-plan model.

\subsection{Financial Leverage Considerations}

Thus far we have implicitly assumed that capital is 100 percent equity financed in the underlying market economy. This section considers the implication of adopting a more realistic assumption. We now suppose that in the underlying market economy, firms issue one-period-ahead risk-free debt, in addition to equity, to finance the acquisition of physical capital. This debt is identical, in maturity and rate of return, to the privately issued bonds whose rate of return we have denoted $r_{t}^{f}$. However, unlike these privately issued bonds, the firm-issued bond is traded in equilibrium. 
As is well-known, profit-maximizing firms are indifferent to the debt-equity composition of their liabilities in an environment such as ours. Moreover, the quantity allocations in general equilibrium are invariant to the pattern, across dates and states of nature, of the debt-to-equity ratio in firm liabilities (the Modigliani-Miller theorem). They solve the same planning problem considered in our preferred two-sector model. What is not invariant to the debt-to-equity ratio is the mean and variance of the return on equity. The premium of the return on equity over debt is strictly increasing in the debt-to-equity ratio. This simply reflects that equity must bear the full degree of uncertainty in firm cash flow across states of nature. In the experiments analyzed below, we consider the equity premium for an economy with a debt-to-equity ratio equal to unity. ${ }^{33}$

Let $\gamma$ denote the debt to equity ratio, and let $r_{l, t+1}^{e *}$ denote the rate of return on equity in sector $l=c, i$, given that the debt to equity ratio is $\gamma=1$. Letting $r_{l, t+1}^{e}$ denote, as before, what the rate of return on equity would be if $\gamma=0$, we have:

$$
r_{l, t+1}^{e *}-r_{t}^{f}=\left(r_{l, t+1}^{e}-r_{t}^{f}\right)(1+\gamma),
$$

for $l=c, i{ }^{34}$ We define the aggregate rate of return on equity, $r_{t+1}^{e *}$, using a

\footnotetext{
${ }^{33}$ This is in line with estimates reported for the US. See Benninga and Protopapadakis (1990) and literature cited there.

${ }^{34}$ For a detailed discussion of a market economy decentralization that rationalizes this formula,
} 
suitably modified version of (3.5).

The parameters in this model coincide with the ones in the one sector model with habit persistence. We assign values to them using the method in section 2.1.2. When we do this, we find that $b=0.69$, a value that is somewhat smaller than the one reported for the preferred two-sector model. The reason for the smaller value of $b$ is that, by directly raising the equity premium, leverage reduces the burden on habit persistence.

To see the asset pricing implications of the model, consider Table 4, 'Immobile, Restricted Labor, w/ Leverage'. Note that the equity premium and risk free rates are still close to their empirical values. Interestingly, on two dimensions there is improvement. First, the standard deviation of the risk free rate is smaller, though it still substantially overstates its empirical value. Now, the standard deviation overstates the empirical value by a factor of three, while with $\gamma=0$ it overstates by a factor of five. The reason for this change has to do with the lower value of $b$ in the model with leverage. Similarly, that model also implies a lower value for the standard deviation of stock prices. The new value is now well within the 95 percent confidence interval for the corresponding empirical estimate.

Table 5 reports the implications of the model for business cycles. Note that the

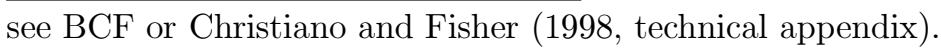


model's implications are essentially indistinguishable from those of the preferred two-sector model. Overall, we conclude that the model with leverage represents a slight improvement over the model without it. However, the improvement is sufficiently small that we feel justified in maintaining our preferred two-sector model with $\gamma=0$ analyzed in section 3.1 as our preferred model. ${ }^{35}$

\section{Other Business Cycle Implications of the Models}

In the previous sections we considered the implications for asset prices and standard business cycle statistics, including persistence, of three classes of models. We identified a 'best' model in each class. These are the time-to-plan, adjustment cost and preferred two-sector models. The three models perform roughly equally well on asset prices. However, the preferred two-sector model emerged as modestly best when we considered the standard business cycle statistics and measures of persistence. Here, we expand the set of business cycle statistics and find that now the preferred two-sector model emerges as clearly the best.

The new set of business cycle statistics that we consider include measures of:

\footnotetext{
${ }^{35}$ Interestingly, the impact of leverage on our 'second best' model, the time-to-plan model, is roughly the same as it is in our preferred two-sector model. Thus, when we reestimate the time-to-plan model imposing $\gamma=1$, we obtain $b=0.60$, which is lower than the value of $b=0.66$ reported for the case $\gamma=0$. In addition, we obtain the following statistics for the variables in Table 2: $1.41,6.63,17.9,25.4,0.26,8.66,0.14$. For Table 3, the results are: 2.06, 0.92, 1.66, $0.58,0.85,0.85,0.87$.
} 
(i) the tendency for employment in different economic sectors to move up and down together over the business cycle; (ii) the tendency for the predictable part of consumption growth to be relatively strongly associated with the predictable part of income growth and weakly associated with the real interest rate; and (iii) the tendency for high real interest rates to be associated with low future output and high past output.

The preferred two-sector model emerges as best because it does clearly better than the other two on (i) and no worse than the other two on the remaining phenomena. All three models do roughly equally well on (ii). Finally, the timeto-plan and preferred two-sector models do best on (iii). The adjustment cost model does particularly poorly on (i) and also does poorly on (ii).

\subsection{Comovement of Employment}

A key feature of business cycles, emphasized at least since the time of Burns and Mitchell (1946, p. 3), is that employment in a broad set of sectors moves up and down together during recessions and expansions. This aspect of business cycles has proved surprisingly difficult to model, although some progress has occurred. Interestingly, our preferred two-sector model is consistent with employment co-

movement. To see this, consider Table 6, Panel A. There we display the correlation 
with output of $H_{c, t}$ and $H_{i, t}$. Note how both of these are positive. ${ }^{36}$

The intuition underlying this result is simple, and can be obtained by studying Figure 2. This exhibits the dynamic responses of sectoral employment to a technology shock in the preferred two-sector model and the two-sector model with mobile, but restricted labor. Note how it is that in the latter model $H_{c, t}$ drops and $H_{i, t}$ rises after a positive shock to technology. The reason is that with the positive technology shock, there is a sharp rise in the demand for investment goods. In the preferred two-sector model things are very different, because labor cannot be reallocated between sectors in the period of the shock. As a consequence, there is a surge in consumption output in that period. In the following periods, the value of consumption goods is high because of the interaction between habit persistence in preferences and the high level of consumption in the first period. This high value of consumption output in the periods after the technology shock accounts for the inflow of labor into that sector in those periods.

We now consider the ability of our one sector models to account for comovement. Technically, the time-to-plan model is capable of accounting for employment comovement. However, it is a Pyrrhic victory for that model. To explain

\footnotetext{
${ }^{36}$ This is a place where the indivisible labor assumption matters. When this utility function is replaced by the divisible labor version, we find that the correlation between $H_{c, t}$ and aggregate output is slightly negative. The reason why the indivisible labor assumption helps comovement is discussed in Christiano and Fisher (1998).
} 
this, recall the discussion in section 3, which noted that there is a two-sector interpretation of the time-to-plan model. Under that interpretation, we can compute $H_{c, t}$ and $H_{i, t}$. When we do this, we find that the response of both variables to a positive technology shock is generally positive. ${ }^{37}$ This is why this model implies that both $H_{c, t}$ and $H_{i, t}$ are procyclical (see Table 6, Panel A). But, ultimately we find the time-to-plan model's explanation of comovement unconvincing. This is because under the two-sector interpretation of the time-to-plan model, the restricted labor assumption is implausible. The type of considerations which motivate the assumption that aggregate labor is difficult to adjust flexibly in response to shocks seem to suggest that it is difficult to flexibly shift labor across economic sectors too. Yet, the time-to-plan model allows such movements to occur freely. Of course, the two-sector interpretation of the time-to-plan model is not the only one possible. Another interpretation is simply that (2.2) produces a homogeneous, intermediate output good, which is split into consumption and investment by final goods firms using (2.4). However, it is not clear that this interpretation provides

\footnotetext{
${ }^{37}$ The explanation mirrors the explanation of comovement in the preferred two-sector model. In the period of the shock $H_{i, t}$ actually drops temporarily because of the predetermined nature of $I_{t}$. Since $H_{t}$ is also predetermined, this means that $H_{c, t}$ surges in the period that a positive shock occurs. In subsequent periods there is a strong motive to increase $H_{i, t}$, as the demand for investment goods rises. But, $H_{c, t}$ rises then too because the value of the output of the consumption sector is high in the periods after the shock. As in the preferred two-sector model, this reflects the interaction between habit persistence in preferences and the surge in consumption that occurs in the period of the shock.
} 
the basis for an interesting explanation of comovement.

Now consider the adjustment cost model. This model also has a two-sector interpretation, and under this interpretation it has implications for $H_{c, t}$ and $H_{i, t}$. When we compute the response of these variables to a positive technology shock, however, we find that $H_{c, t}$ drops and $H_{i, t}$ rises, after a technology shock. As a result, when we compute the correlation of these variables with output we find that $H_{c, t}$ is countercyclical and $H_{i, t}$ is procylical. Thus, even if we ignore the implausibility of the restricted labor assumption under the two-sector interpretation of the adjustment cost model, we find that the model is completely inconsistent with comovement.

To conclude, in our view the observations about comovement provide a compelling basis for choosing our preferred two-sector model over the other two models which also do well on asset prices and standard business cycle statistics.

\subsection{Excess Sensitivity of Consumption to Income}

We now turn to the statistical evidence which Campbell and Mankiw (1989, 1991) (CM) argue is a puzzle from the perspective of equilibrium business cycle models. They estimate a linear expression relating the predictable component of consumption growth to the predictable component of income growth and to the interest 
rate. Applying instrumental variables techniques, they find that the estimated coefficient on income, $\lambda$, is about $1 / 2$, while the coefficient on the interest rate, $\theta$, is close to zero. Appealing to standard optimizing models, CM argue that household maximization implies the coefficient on income should be zero and the coefficient on the interest rate should be large. In these models, the level of consumption is determined by household wealth and its growth rate is determined solely by the rate of interest. The coefficient on the interest rate is the reciprocal of the coefficient of relative risk aversion. This coefficient should be substantially above zero on the assumption that risk aversion is small.

$\mathrm{CM}$ interpret the evidence as indicating that the representative agent, optimizing framework should be abandoned as a way of thinking about fluctuations. Our results suggest another interpretation. We show that the modifications introduced into the standard RBC model to help it account for asset prices also have the effect of raising the implied estimated value of $\lambda$ and reducing the implied estimated value of $\theta$. Thus, an alternative interpretation of CM's findings is that they provide corroborating evidence in favor of these modifications. ${ }^{38}$

Our preferred two-sector model's ability to generate a high value for $\lambda$ reflects

\footnotetext{
${ }^{38}$ Baxter and Jermann (1999) document that a model with home production can also account for the excess sensitivity puzzle.
} 
that, under habit persistence, the intertemporal Euler equation relates consumption growth to lagged consumption growth, as well as to expectations of future consumption growth. In this case, the apparent excess sensitivity to income reflects income's statistical role as a proxy for these variables. The model's ability to generate a low value of $\theta$ is perhaps not surprising in view of the fact that, at our estimated value for $b$, intertemporal substitution in consumption is low. Because agents in our model also have low risk aversion, our framework provides a formal basis for Hall's (1988) suggestion that the weak empirical relation between consumption growth and the interest rate should be interpreted as reflecting low intertemporal substitution in consumption instead of high risk aversion.

The statistical relation that is a primary focus of CM's analysis is:

$$
\Delta C_{t}=\mu+\lambda \Delta Y_{t}+\theta r_{t-1}^{f}+\varepsilon_{t},
$$

where, $\Delta u_{t} \equiv \log \left(u_{t}\right)-\log \left(u_{t-1}\right)$. CM estimate $\mu, \lambda$ and $\theta$ by the following twostep instrumental variables procedure: in the first step they replace the left and right hand side variables in (4.1) by their fitted values, after regression on a set of instruments; in the second step they run an ordinary least squares regression on this modified version of (4.1) to estimate $\mu, \lambda$ and $\theta$. The first column of Table 
6, Panel B, displays a typical set of results reported by CM for these parameter values (see Campbell and Mankiw (1989, Table 5, row 3).)

Table 6, Panel B also summarizes our models' implications for the CM regression. We report two sets of results. One is the mean, in samples of typical size, of instrumental variables regressions in which the instrument list is $\left\{\Delta C_{t-2}, \Delta C_{t-3}, \Delta C_{t-4}, r_{t-3}^{f}, r_{t-4}^{f}, r_{t-5}^{f}\right\}$. This instrument list was chosen because it is representative of the type used in the literature. Our second set of results, reported in square brackets, is designed to help quantify the extent to which our first set of results may reflect small sample distortions. The distortions that concern us are the type that can occur in instrumental variables estimators when the instruments are not very informative for the right hand variables. ${ }^{39}$ The results are computed under the assumption that an infinite sample of data and 'ideal' instruments are available. By 'ideal' we mean that the instrument list contains enough information that the fitted values computed in the first stage regressions correspond to the one-period-ahead conditional expectation of the variables in $(4.1){ }^{40}$

\footnotetext{
${ }^{39}$ For a quantitative analysis of this issue in the standard RBC model, see Christiano (1989). For a general discussion, see Nelson and Startz (1990a,b), Shea (1997) and the references they cite.

${ }^{40} \mathrm{We}$ compute a model's implications for these regressions in the following way. To obtain $E_{t-2} \Delta C_{t}$, we use the impulse response functions of $\Delta C_{t}$ to a one-standard deviation shock to technology. The first difference of these impulse responses is our estimate of the moving average
} 
We begin by comparing the large and small sample results reported in Table 6. Note how large the distortions are in the estimator for $\lambda$. The standard RBC model implies that it is biased up, while the other models imply a substantial downward bias. With one exception, the models imply that there is very little distortion in the estimator for $\theta$. The exception is the adjustment cost model, which suggests there is a substantial small sample upward bias. ${ }^{41}$ Altogether, the results indicate that the instruments are relatively uninformative for the righthand variables in (4.1), especially $\Delta Y_{t} \cdot{ }^{42}$ Under the assumption that in real

representation of $\Delta C_{t}$. Write this (ignoring constant terms) as follows:

$$
\Delta C_{t}=a_{0} \varepsilon_{t}+\alpha_{1} \varepsilon_{t-1}+\ldots+\alpha_{N} \varepsilon_{t-N},
$$

where $\varepsilon_{t}=x_{t}-\bar{x}$ (see (2.3).) We set $N=100$. Then,

$$
E_{t-2} \Delta C_{t}=\alpha_{2} \varepsilon_{t-2}+\ldots+\alpha_{N} \varepsilon_{t-N} .
$$

We computed $E_{t-2} \Delta Y_{t}$ and $E_{t-2} r_{t-1}^{f}$ using the same procedure. The second stage regression was performed by projecting $E_{t-2} \Delta C_{t}$ onto $E_{t-2} \Delta Y_{t}$ and $E_{t-2} r_{t-1}^{f}$. The second moments needed to solve this projection were obtained using the moving average representation just described.

To verify that this moving average representation is a good approximation to the nonlinear representation used elsewhere to analyze our models, we carried out the following calculations. We repeated the Monte Carlo experiments reported in Table 6, Panel B using the linear moving average representation as the data generating mechanism and found that the results do not differ significantly from what is reported in the table.

${ }^{41}$ The results in Table 6, Panel B are based on lagging the instruments twice, as in Campbell and Mankiw $(1989,1990)$. Generally, the results in the table are not sensitive to lagging the instruments only once. The exceptions are the large sample properties of the adjustment cost and time-to-plan models. In the former we find $(\lambda, \theta)=(1.45,-0.13)$ and in the latter we find $(\lambda, \theta)=(7.97,0.43)$. These results do show some sensitivity in the coefficient on the interest rate. Still, the sensitivity is not great enough to affect our conclusions.

${ }^{42}$ Shea (1997) describes a partial $R^{2}$ statistic that can be used in empirical analysis to signal when instruments lack informativeness. We do not use that statistic in our analysis because comparison of small and large sample results gives us a more relevant indicator of this. 
world data the instruments are informative, it follows that this is an empirical weakness of our models. ${ }^{43}$ Most likely, this weakness reflects that there is too little persistence and too much collinearity in the model variables. These problems can be repaired by a variety of changes in specification, such as introducing more persistence in exogenous shocks, and adding new sources of shocks. Pursuing these possibilities would take us well beyond the scope of this paper. Still, the evidence we do have suggests that such changes would cause the model's small sample properties to resemble more closely the large sample properties reported in the table, without significantly altering other implications. ${ }^{44}$

The preceding considerations suggest that, with the exception of the adjustment cost model, we should take seriously the models' implications for the small sample mean of $\theta$. However, caution needs to be exercised in interpreting the implications for the small sample mean of $\lambda$. Some weight should also be applied to the large sample results in this case.

We now turn to the implications of the results in Table 6, Panel B for the

\footnotetext{
${ }^{43}$ Of course, there is uncertainty about the validity of our empirical assumption. Still, a case can be made that the empirical instruments are informative (see Christiano (1989)).

${ }^{44}$ Christiano (1989) showed that this is indeed the case for the standard RBC model. He showed that a version of the standard RBC model which includes government spending shocks, takes temporal aggregation effects into account, and has a small amount of additional persistence in the technology shock, has the implication that the small sample instrumental variables estimator is nearly unbiased.
} 
CM statistical findings. Consider first the results for $\theta$. Consistent with CM's observations, the standard RBC model implies this parameter is roughly unity (the reciprocal of risk aversion in that model). This is more than two standard deviations away from the corresponding empirical estimate, and warrants rejecting the standard RBC model. However, the implications for $\theta$ of the time-to-plan and preferred two-sector models both are close to the corresponding empirical value. This reflects that in these models, the coefficient of relative risk aversion (which is unity) and the degree of intertemporal substitution are not connected as they are in the standard RBC model. The implications of the adjustment cost model for $\theta$ are ambiguous, and depend on whether the small sample or the large sample results are emphasized.

Now consider the results for $\lambda$. Note that the standard RBC model's implication for the small sample mean of this variable is consistent with the corresponding empirical value. However, Christiano (1989) shows that this reflects the model's counterfactual implications for instrument quality. Minor perturbations which improve these implications simultaneously drive the small sample results for $\lambda$ towards zero, that is, towards the large sample figure reported in the table. On this basis, we agree with $\mathrm{CM}$ that the empirical results for $\lambda$ also warrant rejecting the standard RBC model. Turning to the other models, note that their implications 
for the precise value of $\lambda$ are ambiguous. As noted above, they depend on whether large or small sample results are considered. However, the qualitative results are not sensitive to which results we look at. Either way, they indicate that, empirically, consumption is not excessively sensitive to income. Ironically, according to these models the real puzzle is not that measured consumption is excessively sensitive to current income. It is instead that consumption is insufficiently sensitive.

\subsection{Inverted Leading Indicator Phenomenon}

It is a well-documented fact that real (and nominal) interest rates covary positively with past (detrended) levels of output and negatively with future levels (see Fiorito and Kollintzas (1994).) This can be seen in Table 6, Panel C, which displays the dynamic correlations between the inflation-adjusted Federal Funds rate and detrended output. Chari, Christiano and Eichenbaum (1995) and King and Watson (1996) have emphasized that these are important observations for models to be consistent with. They represent a key factor underlying the belief of some researchers that monetary policy shocks play an important role in the dynamics of the business cycle. One reason for this belief is that the monetary policy shock interpretation seems straightforward. Another reason, which appears to receive support in the results of King and Watson (1996), reflects the view that 
RBC models are incapable of accounting for the negative association between interest rates and future output. Our results based on the standard RBC model are consistent with this view. However, the models which incorporate changes designed to account for asset returns are not. They are consistent with the inverted leading indicator phenomenon. These models suggest that the dynamic economic behavior attributed to monetary disturbances may, at least in part, also reflect the effects of real disturbances propagated via mechanisms like those captured in the time-to-plan, adjustment cost and preferred two-sector models.

Consider first the standard RBC model. Note from Table 6, Panel C how the correlation between the interest rate and output is positive at all leads and lags. Mechanically, the positive correlation between the interest rate and current and future output reflects that a positive shock to technology drives up the rate of interest and also drives up current and future output. The reason for the rise in the interest rate is that the shock gives rise to a gradual upward response in consumption. The implications of this with the time separable utility function are straightforward: the current increase in consumption drives the current marginal utility of consumption down, but the larger future rise drives future marginal utility down even more. The interest rate rises in response to the positive technology shock because it is the ratio of these two marginal utilities. A related way of 
seeing this is as follows. With the time-separable, log utility function, households prefer a constant level of consumption over time. The positive technology shock drives up future consumption more than present consumption, and for this to be an equilibrium, households must be discouraged from using asset markets to reallocate consumption from the future to the present. It is precisely the rise in the rate of interest which has this effect.

Significantly, the time-to-plan, adjustment cost and preferred two-sector models are consistent with the inverted leading indicator phenomenon. This reflects these models' implication that the rate of interest falls in the period of a positive technology shock. The reasons for this are somewhat different in the time-to-plan and preferred two-sector models, where the inflexibilities are temporary, and in the adjustment cost model, where some of the inflexibilities are persistent. These differences are instructive.

Consider first the models in which the inflexibilities are temporary. In these models, consumption is relatively high in the period of the shock, compared to its value in subsequent periods (see Figure 1). The reasoning above suggests that this should lead to a fall in the rate of interest, assuming habit persistence does not play too great a role. Consistent with this assumption, calculations not reported here show that when $b$ is set to zero in the time-to-plan and preferred two- 
sector models, these models remain consistent with the inverted leading indicator phenomenon.

Now consider the adjustment cost model which is also, at least qualitatively, consistent with the inverted leading indicator phenomenon. According to Figure 1, the time pattern of consumption after a positive technology shock is very different from what it is in the time-to-plan and preferred two-sector models: it shows a gradual rise. As explained above, with time separable preferences this pattern would imply a rise in the rate of interest. But, the relatively high value of $b$ in the adjustment cost model produces the opposite, with the interest rate falling in the period of a shock. Despite the gradual nature of the equilibrium consumption response, households with habit persistence prefer that response to be even more gradual. The fall in the rate of interest is required to discourage them from attempting to use loan markets to achieve this, by reallocating consumption from the present to the future.

Quantitatively, the adjustment cost model does not do as well as the timeto-plan and preferred two-sector models in accounting for the inverted leading indicator phenomenon. Still, we think that model conveys an important lesson. We suspect that the relatively unsmooth consumption response implied by the time-to-plan and preferred two-sector models is counterfactual, although we are 
not aware of data which shows this. The adjustment cost model results suggest that this unattractive feature of these models is not critical to their good performance on the inverted leading indicator phenomenon and the asset return facts. They give us hope that modifications which produce smoother consumption responses can be introduced while not destroying their good empirical performance on these other dimensions.

\section{Summary and Conclusion}

We explored various modifications on a standard RBC model designed to improve its asset pricing implications. Our most successful modification imposes just two simple changes: it introduces habit persistence into preferences and assumes the sectoral and aggregate allocation of capital and labor is determined before the current period realization of uncertainty. These changes add just one additional unknown parameter to the model. We found that with these changes we were not only able to improve upon the standard RBC model's asset pricing implications, but we were also able to substantially improve upon that model's business cycle implications.

We now briefly discuss some of the limitations of the analysis. First, we find (in results not reported here) that our preferred two-sector model implies a 
high correlation between consumption growth and the rate of return on equityhigher than in the data. ${ }^{45}$ Though this is a long-standing problem for the type of equilibrium model used here, we suspect that the problem can be accounted for by various types of measurement problems with consumption and with the price index used to convert asset returns into real terms. ${ }^{46}$ For example, Christiano (1989) shows that incorporating time aggregation effects into measured consumption and measurement error in the price index can have a quantitatively large, negative impact on the standard RBC model's implication for the consumption growth, equity return correlation. Campbell and Cochrane (1998) also document the quantitatively important impact of time aggregation effects on consumption. ${ }^{47}$

A second shortcoming of the model is that, consistent with the findings in Heaton (1995), it overstates the volatility of the risk free rate. Here too, it is not clear how fundamental this problem is for the approach to asset pricing adopted

\footnotetext{
${ }^{45}$ Our model's predicted correlation between consumption growth and the return on equity is over 0.73 , while the corresponding object in the data is closer to a range of 0.0 to 0.3 , depending on which measure of the return on equity one uses (see Christiano 1989).

${ }^{46}$ For a discussion of measurement error in consumption data, see Wilcox (1992). Gibbons (1989) argues that measurement error in consumption data is so severe that those data should not be used at all in evaluating theories of asset pricing.

${ }^{47} \mathrm{We}$ did a computational experiment which shows that in our preferred model, aggregation over time effects on consumption can be quantitatively large. To do this, we constructed a model whose time period is $1 / 8$ times the data sampling interval. We adjusted the depreciation rate on capital and the standard deviation of technology by dividing by 8 . We adjusted the habit parameter so that the model remains consistent with the observed mean risk free rate and mean equity premium. This required setting $b=0.83$. In this model, the correlation between time-averaged consumption growth and the rate of return on equity is only 0.30 .
} 
in this paper. There are results in the literature which give us hope that it is not. For example, Campbell and Cochrane (1998) adopt a more elaborate representation of habit persistence preferences and find that the risk free rate is constant. Similarly, the risk free rate in Constantinides (1990) is also constant. Finally, Abel (1999) presents a model with habit persistence in preferences which also implies a reasonable amount of volatility in the risk free rate. ${ }^{48}$

Third, a key ingredient in our success in obtaining an equity premium is that, in addition to habit persistence in preferences, we introduced features of technology that prevent households from intertemporally smoothing consumption. At the same time, our model has left out an important real-world device for doing this: inventories. Are our results robust to the introduction of inventories? Determining the answer with confidence is beyond the scope of this paper. However, there are at least three reasons for optimism. (i) Inventories are not a perfect intertemporal smoothing device, since services are a substantial part of consumption, and these cannot be stored. (ii) The adjustment cost model analyzed in

\footnotetext{
${ }^{48}$ One difference between Abel's (1999) specification of habit persistence and ours is that he adopts a higher level of risk aversion. In our context, this is also a strategy for reducing the model's implications for the volatility of the risk free rate. This strategy works by reducing the value of $b$ needed to account for the mean risk free rate and mean equity premium. We found that a smaller value of $b$ also reduces the volatility of the risk free rate. A difficulty with this strategy is that, as discussed in section 2.2.2, it tends to make employment countercylical. This implication of high risk aversion is not evident in Abel's (1999) work because he holds labor constant.
} 
the paper offers households slightly more flexible intertemporal smoothing opportunities than does the preferred two-sector model. Nevertheless, that model is consistent with key features of asset returns. This suggests that the frictions in the two-sector model can be weakened (possibly, by introducing inventories) without sacrificing too much on asset returns. (iii) Any modeling approach (based, say on the Campbell and Cochrane (1998) specification of preferences) which solves the excess volatility problem with the risk free rate would simultaneously make inventories unattractive as an intertemporal smoothing device. For example, if the risk free rate were always greater than unity, then inventories would never be held for intertemporal smoothing reasons. This is true under the (plausible) assumption that inventories generate a gross rate of return no greater than unity.

In sum, we believe our model makes progress on the task of integrating asset pricing and business cycles. Still, the model has shortcomings and a final verdict depends on whether these shortcomings turn out to be signals that there is something fundamentally wrong with the model, or whether minor perturbations can overcome them. Assessing this is a task for future research. 


\section{References}

Abel, Andrew, 1990, 'Asset prices under habit formation and catching up with the Joneses,' American Economic Review Papers and Proceedings, vol. 80, pp. 38-42.

Abel, Andrew, 1999, 'Risk Premia and Term Premia in General Equilibrium,' Journal of Monetary Economics, vol. 43, no.1, pages 3-34.

Aiyagari, S. Rao, and Mark Gertler, 1991, 'Asset returns with transactions costs and uninsured individual risks,' Journal of Monetary Economics, vol. 27, pp. $311-332$.

Barsky, Robert, T. Juster, Miles Kimball, and Matthew Shapiro, 1997, 'Preference parameters and behavioral heterogeneity: an experimental approach in the health and retirement study,' Quarterly Journal of Economics, vol. 112, no. 2, May, pages 537-79.

Baxter, Marianne, and Urban J. Jermann, 1999, 'Household production and the excess sensitivity of consumption to current income,' manuscript, Wharton School, University of Pennsylvania.

Benhabib, J., Rogerson, R. and R. Wright, 1991, 'Homework in Macroeconomics: Household Production and Aggregate Fluctuations', Journal of Political Economy, Vol. 99, No.6, 1166 - 1187.

Benninga, Simon, and Aris Protopapadakis, 1990, 'Leverage, time preference, and the 'equity premium puzzle,' Journal of Monetary Economics, vol. 25, pp. $49-58$.

Boldrin, Michele, Lawrence J. Christiano and Jonas D.M. Fisher, 1995, 'Asset Pricing Lessons for Modeling Business Cycles,' National Bureau of Economic Research Working Paper 5262.

Boldrin, Michele, Lawrence J. Christiano and Jonas D.M. Fisher, 1997, 'Habit Persistence and Asset Returns in an Exchange Economy,' Macroeconomic Dynamics, vol. 1, pp. 312-32.

Burns, Arthur, and W. C. Mitchell, 1946, 'Measuring Business Cycles, Studies in Business Cycles,' No. 2, National Bureau of Economic Research. 
Burnside, Craig, 1994, 'Hansen-Jagannathan bounds as classical tests of assetpricing models,' Journal of Business and Economic Statistics, vol. 12, pages $57-79$.

Burnside, Craig, Martin Eichenbaum and Sergio Rebelo, 1993, 'Labor Hoarding and the Business Cycle,' Journal of Political Economy, vol. 101, no. 2, April, pp. 245-273.

Campbell, John Y., and John H. Cochrane, 1998, 'By force of habit: a consumptionbased explanation of aggregate stock market behavior,' manuscript, University of Chicago Graduate School of Business.

Campbell, John Y., Andrew W. Lo and A. Craig MacKinlay, 1997, The Econometrics of Financial Markets, Princeton University Press.

Campbell, John Y., and N. Gregory Mankiw, 1989, 'Consumption, income, and interest rates: reinterpreting the time series evidence,' in Olivier Jean Blanchard and Stanley Fischer, editors, NBER Macroeconomics Annual 1989, pp. $185-216$.

Campbell, John Y., and N. Gregory Mankiw, 1991, 'The response of consumption to income: a cross-country investigation,' European Economic Review, vol. 35 , pp. $723-767$.

Cecchetti, Stephen G., Pok-sang Lam, and Nelson C. Mark, 1993, 'The equity premium and the risk-free rate: matching the moments,' Journal of Monetary Economics, vol. 31, pp. 21-45.

Chari, V.V., Lawrence J. Christiano and Martin Eichenbaum, 1995, 'Inside Money, Outside Money, and Short-Term Interest Rates,' Journal of Money, Credit and Banking, vol. 27, no. 4, part 2, November, pp. 1354-1401.

Christiano, Lawrence J., 1987, 'Is Consumption Insufficiently Sensitive to Innovations in Income?', American Economic Review Papers and Proceedings; 77(2), May, pages 337-41.

Christiano, Lawrence J., 1988, 'Why does inventory investment fluctuate so much?' Journal of Monetary Economics, vol. 21, pp. 247-280. 
Christiano, Lawrence J., 1989, Comment on: 'Consumption, income, and interest rates,' in Oliver Jean Blanchard and Stanley Fischer, editors, NBER Macroeconomics Annual 1989, pp. 216-233.

Christiano, Lawrence J., 1996, 'Identification and the Liquidity Effect: A Case Study,' Federal Reserve Bank of Chicago Economic Perspectives; vol. 20, no. 3 May-June, pp. 2-13.

Christiano, Lawrence J., and Martin Eichenbaum, 1992, 'Current real-business cycle theories and aggregate labor-market fluctuations,' American Economic Review, vol. 82, no. 3, pp. 430-450.

Christiano, Lawrence J., and Jonas D. M. Fisher, 1998, 'Stock Market and Investment Good Prices: Implications for Macroeconomics,' Federal Reserve Bank of Chicago Working paper 98-6.

Christiano, Lawrence J., and Jonas D. M. Fisher, 2000, 'Algorithms for solving dynamic models with occasionally binding constraints,' Journal of Economic Dynamics and Control, vol. 24, pp. 1179-1232.

Christiano, Lawrence J., and Terry J. Fitzgerald, 1998, 'The Business Cycle: It's Still a Puzzle,' Federal Reserve Bank of Chicago Economic Perspectives, vol. 22 , pp. 56-83.

Christiano, Lawrence J., and Richard Todd, 1996, 'Time to Plan and Aggregate Fluctuations,' Federal Reserve Bank of Minneapolis Quarterly Review, vol. 20, Winter, pp. 14-27.

Christiano, Lawrence J., and Robert J. Vigfusson, 1999, 'Maximum Likelihood in the Frequency Domain: A Time to Build Example,' National Bureau of Economic Research Working Paper 7027.

Cochrane, John H., and Lars Peter Hansen, 1992, 'Asset pricing explorations for macroeconomics,' NBER Macroeconomics Annual, pp. 115-165.

Cogley, Tim, and Jim Nason, 1995, 'Output dynamics in real-business cycle models,' American Economic Review, vol. 85, pp. 492-511.

Constantinides, George, 1990, 'Habit formation: a resolution of the equity premium puzzle,' Journal of Political Economy, vol. 98, pp. 519-543. 
Daniel, Kent, and David Marshall, 1998, 'Consumption-Based Modeling of LongHorizon Returns,' Federal Reserve Bank of Chicago Working Paper number 98-18.

Danthine, Jean-Pierre, and John B. Donaldson, 1994, 'Asset pricing implications of real market frictions,' Columbia University, Paine-Webber Working Paper Series in Money, Economics and Finance: 95-04, December.

Danthine, Jean-Pierre, John B. Donaldson, and Rajnish Mehra, 1992, 'The equity premium and the allocation of income risk,' Journal of Economic Dynamics and Control, vol. 16, pp. 509-532.

David, Alex, Seong-Wan Oh, Joseph Ostroy, and Keong-Van Shin, 1992, 'Cyclical fluctuations in uncertainty: An application to the premium on equities,' manuscript, UCLA.

Ferson, Wayne E., and George M. Constantinides, 1991, 'Habit persistence and durability in aggregate consumption: empirical tests,' Journal of Financial Economics, vol. 29, pp. 199-240.

Fiorito, Riccardo and Tryphon Kollintzas, 1994, 'Stylized Facts of Business Cycles in the G7 from a Real Business Cycles Perspective,' European Economic Review, vol. 38, no. 2, pp. 235-69.

Fisher, Jonas, 1997, 'Relative Prices, Complementarities and Comovement Among Components of Aggregate Expenditures,' Journal of Monetary Economics, vol. 39, pages 449-474.

Gertler, Mark, and Simon Gilchrist, 1999, 'Hump-Shaped Output Dynamics in a Forward Looking Model: The Role of Time to Plan,' manuscript, New York University.

Gibbons, Michael R., 1989, 'On the volatility of bond prices,' Carnegie-Rochester Conference Series on Public Policy, vol. 31, pp. 139-175.

Goolsbee, Austan, 1998, 'Investment Tax Incentives, Prices, and the Supply of Capital Goods,' Quarterly Journal of Economics, 113(1), February, pp. 121 $-148$.

Hall, Robert E., 1978, 'Stochastic implications of the life cycle-permanent income hypothesis,' Journal of Political Economy, vol. 86, pp. 971-87. 
Hall, Robert E., 1988, 'Intertemporal substitution in consumption,' Journal of Political Economy, vol. 96, pp. 339-357.

Hansen, Gary, 1985, 'Indivisible Labor and the Business Cycle,' Journal of Monetary Economics, 16(3), November, pages 309-27.

Hansen, Lars Peter, and Kenneth J. Singleton, 1982, 'Generalized instrumental variables estimation of nonlinear rational expectations models,' Econometrica, vol. 50, pp. 1269-1286.

Hansen, Lars Peter, and Kenneth J. Singleton, 1983, 'Stochastic consumption, risk aversion, and the temporal behavior of asset returns,' Journal of Political Economy, vol. 91, pp. 249-265.

Heaton, John, 1995, 'An empirical investigation of asset pricing with temporally dependent preference specifications,' Econometrica, vol. 63, pp. 681-717.

Heaton, John, and Deborah Lucas, 1992, 'The effects of incomplete insurance markets and trading costs in a consumption-based asset pricing model,' Journal of Economic Dynamics and Control, vol. 16, pp. 601-20.

Heaton, John, and Deborah Lucas, 1996, 'Evaluating the effects of incomplete markets on risk sharing and asset pricing,' Journal of Political Economy, vol. 104, pp. 443-487.

Jermann, Urban J., 1998, 'Asset pricing in production economies,' Journal of Monetary Economics, vol. 41, pp. 257-276.

Judd, Kenneth L., 1998, Numerical Methods in Economics, Cambridge and London: MIT Press.

Kandel, Shmuel and Robert F. Stambaugh, 1991, 'Asset returns and intertemporal preferences,' Journal of Monetary Economics, vol. 27, pp. 39-71.

King, Robert and Mark Watson, 1996, 'Money, Prices, Interest Rates and the Business Cycle,' Review of Economics and Statistics, vol. LXXVIII, no. 1, pp. 35-53.

Lettau, Martin, and Harald Uhlig, 1995, 'Can habit formation be reconciled with business cycle facts?' manuscript, CentER for Economic Research, Tilburg University. 
Lettau, Martin, and Harald Uhlig, 1997, 'Preferences, consumption smoothing, and risk premia,' manuscript, CentER for Economic Research.

Ljungqvist, Lars and Harald Uhlig, 1999, 'Catching up with the Keynesians,' manuscript, CentER for Economic Research, Tilburg University, February.

Mankiw, N. Gregory, 1986, 'The equity premium and the concentration of aggregate shocks,' Journal of Financial Economics, vol. 17, pp. 211-219.

Mehra, Rajnish, and Edward C. Prescott, 1985, 'The equity premium: a puzzle,' Journal of Monetary Economics, vol. 15, pp. 145-161.

Nason, James N., 1988, 'The equity premium and time-varying risk behavior,' Finance and Economics Discussion Series, No. 11 (Board of Governors of the Federal Reserve, Washington, DC).

Nelson, Charles R., and Richard Startz, 1990a, 'The distribution of the instrumental variables estimator and its $t$-ratio when the instrument is a poor one,' Journal of Business, vol. 63, no. 1, part 2, pp. S125-140.

Nelson, Charles R., and Richard Startz, 1990b, 'Some further results on the exact small sample properties of the instrumental variable estimator,' Econometrica, vol. 58, pp. 967-976.

Phelan, Christopher and Alberto Trejos, 1996, 'On the Aggregate Effects of Sectoral Reallocations,' Northwestern University manuscript.

Ramey, Valerie, and Matthew Shapiro, 1998, 'Displaced Capital,' National Bureau of Economic Research Working Paper number 6775.

Reitz, T.A., 1988, 'The equity premium: a solution,' Journal of Monetary Economics, vol. 22, pp. 117-133.

Rogerson, Richard, 1988, 'Indivisible Labor, Lotteries and Equilibrium', Journal of Monetary Economics, 21(1), January, pages 3-16.

Sargent, Thomas, 1980, 'Tobin's $q$ and the Rate of Investment in General Equilibrium,' Carnegie-Rochester Conference Series on Public Policy, 12, 107-54.

Shea, John, 1997, 'Instrument Relevance in Multivariate Linear Models: A Simple Measure,' Review of Economics and Statistics; 79(2), May, pages 348-52. 
Sundaresan, Suresh M., 1989, 'Intertemporally dependent preferences and the volatility of consumption and wealth,' Review of Financial Studies, vol. 2, pp. 73-89.

Tallarini, Thomas D., Jr., 1998, 'Risk-sensitive real business cycles,' manuscript, Carnegie-Mellon University.

Tsionas, E.G., 1994, 'Asset returns in general equilibrium with scale mixture of normal endowment processes,' Unpublished University of Minnesota Ph.D. Dissertation.

Weil, Philippe, 1989, 'The equity premium puzzle and the risk-free rate puzzle,' Journal of Monetary Economics, vol. 24, pp. 401-421.

Weil, Philippe, 1992, 'Comment on 'Asset pricing explorations for macroeconomics,'’ NBER Macroeconomics Annual 1992, pp. 169-181.

Wilcox, David W., 1992, 'The construction of U.S. consumption data: some facts and their implications for empirical work,' American Economic Review, vol. 82, no. 4, pp. 922-941. 
Table 1. Summary of models used in the analysis

\begin{tabular}{|c|c|c|c|c|c|c|c|c|}
\hline \multirow[b]{2}{*}{ Full Name } & \multirow[b]{2}{*}{ Abbreviated Name } & \multicolumn{2}{|c|}{ Aggregate Decision } & \multicolumn{2}{|c|}{ Sectoral Decision } & \multirow{2}{*}{$\begin{array}{c}\text { Adjustment costs } \\
\text { on investment }\end{array}$} & \multirow{2}{*}{$\begin{array}{c}\text { Habit } \\
\text { Persistence }\end{array}$} & \multirow{2}{*}{$\begin{array}{l}\text { Financial } \\
\text { Leverage }\end{array}$} \\
\hline & & Labor & Investment & Labor & Capital & & & \\
\hline \multicolumn{9}{|c|}{ One Sector Models } \\
\hline Unrestricted Labor & \multirow{5}{*}{ Standard RBC } & & & & & & & \\
\hline $\mathrm{RBC}$ & & After $\theta_{t}$ & After $\theta_{t}$ & na & na & No & $b=0$ & No \\
\hline $\mathrm{RBC}$ & & After $\theta_{t}$ & After $\theta_{t}$ & na & na & No & $b>0$ & No \\
\hline Adjustment Cost & & After $\theta_{t}$ & After $\theta_{t}$ & na & na & Yes & $b>0$ & No \\
\hline Time-to-plan & & After $\theta_{t}$ & Before $\theta_{t}$ & na & na & No & $b>0$ & No \\
\hline \multicolumn{9}{|l|}{ Restricted Labor } \\
\hline $\mathrm{RBC}$ & \multirow{3}{*}{$\begin{array}{l}\text { Adjustment Cost } \\
\text { Time-to-plan }\end{array}$} & \multirow{4}{*}{$\begin{array}{l}\text { Before } \theta_{t} \\
\text { Before } \theta_{t} \\
\text { Before } \theta_{t}\end{array}$} & \multirow{3}{*}{$\begin{array}{c}\text { After } \theta_{t} \\
\text { After } \theta_{t} \\
\text { Before } \theta_{t}\end{array}$} & \multirow{3}{*}{$\begin{array}{l}\text { na } \\
\text { na } \\
\text { na }\end{array}$} & na & \multirow{3}{*}{$\begin{array}{l}\text { No } \\
\text { Yes } \\
\text { No }\end{array}$} & \multirow{3}{*}{$\begin{array}{l}b \geq 0 \\
b>0 \\
b>0\end{array}$} & \multirow{3}{*}{$\begin{array}{l}\text { No } \\
\text { No } \\
\text { No }\end{array}$} \\
\hline Adjustment Cost & & & & & na & & & \\
\hline Time-to-plan & & & & & na & & & \\
\hline \multicolumn{8}{|c|}{ Two Sector Models } & \\
\hline \multicolumn{9}{|l|}{ Mobile Labor } \\
\hline Unrestricted Labor & & After $\theta_{t}$ & After $\theta_{t}$ & After $\theta_{t}$ & Before $\theta_{t}$ & No & $b \geq 0$ & No \\
\hline Restricted Labor & & Before $\theta_{t}$ & After $\theta_{t}$ & After $\theta_{t}$ & Before $\theta_{t}$ & No & $b \geq 0$ & No \\
\hline \multicolumn{9}{|l|}{ Immobile, Restricted Labor } \\
\hline No Leverage & Preferred two-sector & Before $\theta_{t}$ & After $\theta_{t}$ & Before $\theta_{t}$ & Before $\theta_{t}$ & No & $b \geq 0$ & No \\
\hline With Leverage & & Before $\theta_{t}$ & After $\theta_{t}$ & Before $\theta_{t}$ & Before $\theta_{t}$ & No & $b>0$ & Yes \\
\hline
\end{tabular}

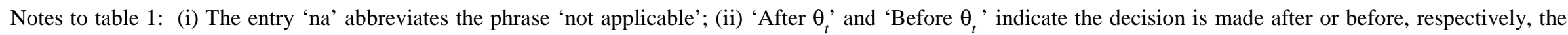

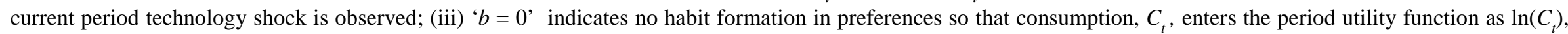

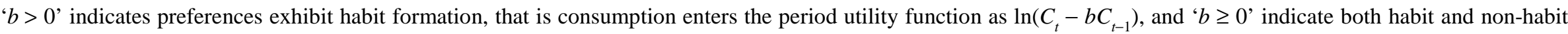
formation preferences are considered. 
Table 2. Financial statistics in the one-sector models

\begin{tabular}{|c|c|c|c|c|c|c|c|c|c|}
\hline \multirow[b]{3}{*}{ Statistic } & \multirow[b]{3}{*}{ Data } & \multicolumn{4}{|c|}{ Unrestricted Labor } & \multicolumn{4}{|c|}{ Restricted Labor } \\
\hline & & \multicolumn{2}{|c|}{$\mathrm{RBC}$} & \multirow{2}{*}{$\begin{array}{l}\text { Adjustment Cost } \\
\qquad b=0.9\end{array}$} & \multirow{2}{*}{$\begin{array}{c}\text { Time-to-Plan } \\
b=0.9\end{array}$} & \multicolumn{2}{|c|}{$\mathrm{RBC}$} & \multirow{2}{*}{$\begin{array}{c}\text { Adjustment Cost } \\
\qquad b=0.9\end{array}$} & \multirow{2}{*}{$\begin{array}{c}\text { Time-to-Plan } \\
b=0.66\end{array}$} \\
\hline & & $b=0$ & $b=0.9$ & & & $b=0$ & $b=0.9$ & & \\
\hline$E r_{t}^{f}$ & $\begin{array}{c}1.19 \\
(0.81)\end{array}$ & 1.58 & 1.58 & 1.55 & 1.56 & 1.59 & 1.58 & 1.19 & 1.34 \\
\hline$E\left(r_{t+1}^{e}-r_{t}^{f}\right)$ & $\begin{array}{c}6.63 \\
(1.78)\end{array}$ & 0.001 & 0.001 & 0.15 & 0.05 & 0.001 & 0.001 & 4.47 & 6.63 \\
\hline$\sigma_{r^{f}}$ & $\begin{array}{c}5.27 \\
(0.74)\end{array}$ & 0.46 & 0.38 & 0.30 & 1.47 & 0.47 & 0.39 & 18.0 & 25.4 \\
\hline$\sigma_{r^{e}}$ & $\begin{array}{c}19.4 \\
(1.56)\end{array}$ & 0.48 & 0.40 & 5.53 & 1.08 & 0.48 & 0.40 & 16.3 & 19.0 \\
\hline$\frac{E\left(r_{t+1}^{e}-r_{t}^{f}\right)}{\sigma_{r^{e}}}$ & $\begin{array}{c}0.34 \\
(0.09)\end{array}$ & 0.002 & 0.002 & 0.03 & 0.05 & 0.001 & 0.002 & 0.27 & 0.35 \\
\hline$\sigma_{P_{k^{\prime}}}$ & $\begin{array}{c}8.56 \\
(0.85)\end{array}$ & 0 & 0 & 3.59 & 0.75 & 0 & 0 & 10.8 & 12.3 \\
\hline$\rho\left(Y, P_{k^{\prime}}\right)$ & $\begin{array}{c}0.30 \\
(0.08)\end{array}$ & na & na & 0.43 & -0.35 & na & na & 0.89 & 0.14 \\
\hline
\end{tabular}

Notes to table 2: (i) For explanations of the model names, see Table 1; (ii) $\sigma_{x}$ denotes the standard deviation of variable $x$ and $\rho(x, y)$ denotes the correlation between variable $x$ and variable $y$. Rates of returns are annualized in the percent terms before statistics are computed; (iii) The "Data" column contains estimates (standard errors in parenthesis) based on U.S. data. The sample period for the asset return estimates is 1892-1987 and these estimates are taken from Cecchetti, Lam, and Mark (1993). Our empirical analogue for $P_{k^{\prime}}$ is the S\&P 500 composite (DRI database mneumonic FSPCOM). The output measure and the procedure for estimating $\sigma_{P_{k^{\prime}}}$ and $\rho\left(Y, P_{k^{\prime}}\right)$ is described in note (iii), Table 3; (iv) Results for the models are based on 500 replications of sample size 200; (vi) The entry 'na' abbreviates 'not applicable.' 
Table 3. Basic business cycle statistics in the one-sector models

\begin{tabular}{|c|c|c|c|c|c|c|c|c|c|}
\hline \multirow[b]{3}{*}{ Statistic } & \multirow[b]{3}{*}{ Data } & \multicolumn{4}{|c|}{ Unrestricted Labor } & \multicolumn{4}{|c|}{ Restricted Labor } \\
\hline & & \multicolumn{2}{|c|}{$\mathrm{RBC}$} & \multirow{2}{*}{$\begin{array}{l}\text { Adjustment Cost } \\
\qquad b=0.9\end{array}$} & \multirow{2}{*}{$\begin{array}{l}\text { Time-to-plan } \\
b=0.9\end{array}$} & \multicolumn{2}{|c|}{$\mathrm{RBC}$} & \multirow{2}{*}{$\begin{array}{l}\text { Adjustment Cost } \\
\qquad b=0.9\end{array}$} & \multirow{2}{*}{$\begin{array}{l}\text { Time-to-plan } \\
\quad b=0.66\end{array}$} \\
\hline & & $b=0$ & $b=0.9$ & & & $b=0$ & $b=0.9$ & & \\
\hline \multicolumn{10}{|c|}{ Panel A - Standard Statistics } \\
\hline$\sigma_{Y}$ & $\begin{array}{c}1.89 \\
(0.21)\end{array}$ & 2.11 & 1.79 & 0.60 & 1.77 & 1.98 & 1.72 & 1.04 & 2.07 \\
\hline$\sigma_{C} / \sigma_{Y}$ & $\begin{array}{c}0.40 \\
(0.04)\end{array}$ & 0.53 & 0.30 & 1.02 & 0.28 & 0.56 & 0.31 & 0.66 & 0.94 \\
\hline$\sigma_{I} / \sigma_{Y}$ & $\begin{array}{c}2.39 \\
(0.06)\end{array}$ & 1.86 & 2.58 & 1.35 & 2.52 & 1.84 & 2.55 & 2.31 & 1.61 \\
\hline$\sigma_{H} / \sigma_{Y}$ & $\begin{array}{c}0.80 \\
(0.05)\end{array}$ & 0.48 & 0.27 & 2.73 & 1.05 & 0.50 & 0.28 & 1.28 & 0.58 \\
\hline$\rho(Y, C)$ & $\begin{array}{l}0.76 \\
(0.05)\end{array}$ & 0.99 & 0.48 & 0.91 & 0.63 & 0.98 & 0.53 & 0.53 & 0.86 \\
\hline$\rho(Y, I)$ & $\begin{array}{c}0.96 \\
(0.01)\end{array}$ & 0.99 & 0.98 & 0.83 & 0.99 & 0.99 & 0.98 & 0.91 & 0.84 \\
\hline$\rho(Y, H)$ & $\begin{array}{c}0.78 \\
(0.05)\end{array}$ & 0.99 & 0.99 & -0.60 & 0.58 & 0.86 & 0.82 & -0.21 & 0.87 \\
\hline \multicolumn{10}{|c|}{ Panel B - Persistence Statistics } \\
\hline$\rho(\Delta Y)$ & $\begin{array}{c}0.34 \\
(0.07)\end{array}$ & 0.002 & 0.02 & 0.38 & 0.07 & 0.36 & 0.21 & -0.44 & 0.40 \\
\hline$\rho(\Delta C)$ & $\begin{array}{c}0.24 \\
(0.09)\end{array}$ & 0.05 & 0.90 & 0.86 & 0.79 & 0.05 & 0.90 & 0.68 & -0.14 \\
\hline
\end{tabular}

Notes to Table 3: (i) For explanations of the model names see Table 1; (ii) $\sigma_{x}$ denotes the standard deviation of variable $x, \rho(x, y)$ denotes the correlation between $x$ and variable $y$, where $x$ and $y$ are logged and HP filtered prior to analysis, and $\rho(\Delta x)$ denotes the autocorrelation of log $x_{t}-\log x_{t-1}$. The statistic $\sigma_{Y}$ is reported in percent terms; (iii) The "Data" column contains estimates (standard errors in parenthesis) based on an updated version of the Christiano (1988) database compiled by Fisher (1997) covering the sample period 1964:1-1988:2. The standard errors are based on the GMM procedure described in Christiano and Eichenbaum (1992). For estimation of the relevant zero-frequency spectral density, a Bartlett window truncated at lag four, was used. (iv) Results for the model are based on 500 replications of sample size 200. 
Table 4. Financial statistics in the two-sector models

\begin{tabular}{|c|c|c|c|c|c|c|c|c|c|}
\hline \multirow[b]{2}{*}{ Statistic } & \multirow[b]{2}{*}{ Data } & & \multicolumn{4}{|c|}{ Mobile Labor } & \multirow{2}{*}{$\begin{array}{c}\text { Immobile, } \\
\text { Restricted Labor } \\
b=0\end{array}$} & \multirow{2}{*}{$\begin{array}{c}\text { Preferred } \\
\text { Two-sector } \\
b=0.73\end{array}$} & \multirow{2}{*}{$\begin{array}{c}\text { Immobile, Restricted } \\
\text { Labor, w/ Leverage } \\
b=0.69\end{array}$} \\
\hline & & $\begin{array}{c}\text { Standard } \\
\text { RBC }\end{array}$ & $\begin{array}{c}\text { Unres } \\
b=0\end{array}$ & $\begin{array}{l}\text { ted Labor } \\
b=0.9\end{array}$ & $\begin{array}{l}\text { Restr } \\
b=0\end{array}$ & $\begin{array}{c}\text { ed Labor } \\
b=0.9\end{array}$ & & & \\
\hline$E r_{t}^{f}$ & $\begin{array}{c}1.19 \\
(0.81)\end{array}$ & 1.58 & 1.59 & 1.56 & 1.58 & 1.56 & 1.58 & 1.20 & 1.32 \\
\hline$E\left(r_{t+1}^{e}-r_{t}^{f}\right)$ & $\begin{array}{c}6.63 \\
(1.78)\end{array}$ & 0.001 & 0.01 & 0.04 & 0.01 & 0.05 & 0.02 & 6.63 & 6.63 \\
\hline$\sigma_{r^{f}}$ & $\begin{array}{c}5.27 \\
(0.74)\end{array}$ & 0.46 & 1.15 & 2.82 & 0.63 & 1.34 & 0.62 & 24.6 & 17.2 \\
\hline$\sigma_{r^{e}}$ & $\begin{array}{c}19.4 \\
(1.56)\end{array}$ & 0.48 & 1.74 & 4.07 & 0.58 & 1.01 & 0.57 & 18.4 & 24.9 \\
\hline$\frac{E\left(r_{t+1}^{e}-r_{t}^{f}\right)}{\sigma_{r^{e}}}$ & $\begin{array}{c}0.34 \\
(0.09)\end{array}$ & 0.002 & 0.005 & 0.01 & 0.02 & 0.05 & 0.03 & 0.36 & 0.27 \\
\hline$\sigma_{P_{k^{\prime}}}$ & $\begin{array}{c}8.56 \\
(0.85)\end{array}$ & 0 & 0.29 & 0.70 & 0.30 & 0.69 & 0.29 & 12.1 & 8.43 \\
\hline$\rho\left(Y, P_{k^{\prime}}\right)$ & $\begin{array}{c}0.30 \\
(0.08)\end{array}$ & na & 0.25 & -0.08 & 0.16 & 0.25 & 0.16 & 0.16 & 0.16 \\
\hline
\end{tabular}

Note to Table 4: See the notes to Table 2. 
Table 5. Basic business cycle statistics in the two-sector models

\begin{tabular}{|c|c|c|c|c|c|c|c|c|c|}
\hline Statistic & Data & $\begin{array}{c}\text { Standard } \\
\text { RBC }\end{array}$ & $\begin{array}{l}\text { Unrest } \\
b=0\end{array}$ & $\begin{array}{r}\text { Mobile } \\
\text { ted Labor } \\
b=0.9\end{array}$ & $\begin{array}{l}\text { Labor } \\
\text { Restri } \\
b=0\end{array}$ & $\begin{array}{l}\text { d Labor } \\
b=0.9\end{array}$ & $\begin{array}{c}\text { Immobile, } \\
\text { Restricted Labor } \\
b=0\end{array}$ & $\begin{array}{c}\text { Preferred } \\
\text { Two-sector } \\
b=0.73\end{array}$ & $\begin{array}{c}\text { Immobile, Restricted } \\
\text { Labor, w/ Leverage } \\
b=0.69\end{array}$ \\
\hline \multicolumn{10}{|c|}{ Panel A - Standard Statistics } \\
\hline$\sigma_{Y}$ & $\begin{array}{c}1.89 \\
(0.21)\end{array}$ & 2.11 & 2.00 & 1.66 & 1.97 & 1.71 & 1.96 & 1.97 & 1.97 \\
\hline$\sigma_{C} / \sigma_{Y}$ & $\begin{array}{c}0.40 \\
(0.04)\end{array}$ & 0.53 & 0.61 & 0.32 & 0.62 & 0.32 & 0.62 & 0.69 & 0.68 \\
\hline$\sigma_{I} / \sigma_{Y}$ & $\begin{array}{c}2.39 \\
(0.06)\end{array}$ & 1.86 & 1.79 & 2.48 & 1.84 & 2.53 & 1.83 & 1.67 & 1.69 \\
\hline$\sigma_{H} / \sigma_{Y}$ & $\begin{array}{c}0.80 \\
(0.05)\end{array}$ & 0.48 & 0.46 & 0.67 & 0.51 & 0.28 & 0.50 & 0.51 & 0.51 \\
\hline$\rho(Y, C)$ & $\begin{array}{c}0.76 \\
(0.05)\end{array}$ & 0.99 & 0.95 & 0.63 & 0.91 & 0.55 & 0.92 & 0.95 & 0.95 \\
\hline$\rho(Y, I)$ & $\begin{array}{c}0.96 \\
(0.01)\end{array}$ & 0.99 & 0.98 & 0.98 & 0.97 & 0.98 & 0.97 & 0.97 & 0.97 \\
\hline$\rho(Y, H)$ & $\begin{array}{c}0.78 \\
(0.05) \\
\end{array}$ & 0.99 & 0.94 & 0.48 & 0.86 & 0.81 & 0.86 & 0.86 & 0.86 \\
\hline \multicolumn{10}{|c|}{ Panel B- Persistence Statistics } \\
\hline$\rho\left(\Delta Y_{t}\right)$ & $\begin{array}{c}0.34 \\
(0.07)\end{array}$ & 0.002 & 0.21 & 0.49 & 0.36 & 0.21 & 0.36 & 0.36 & 0.36 \\
\hline$\rho\left(\Delta C_{t}\right)$ & $\begin{array}{c}0.24 \\
(0.09)\end{array}$ & 0.05 & -0.22 & 0.88 & -0.23 & 0.88 & -0.22 & -0.05 & -0.06 \\
\hline
\end{tabular}

Note to Table 5: See the notes to Table 3. 
Table 6. Other business cycle statistics in selected models

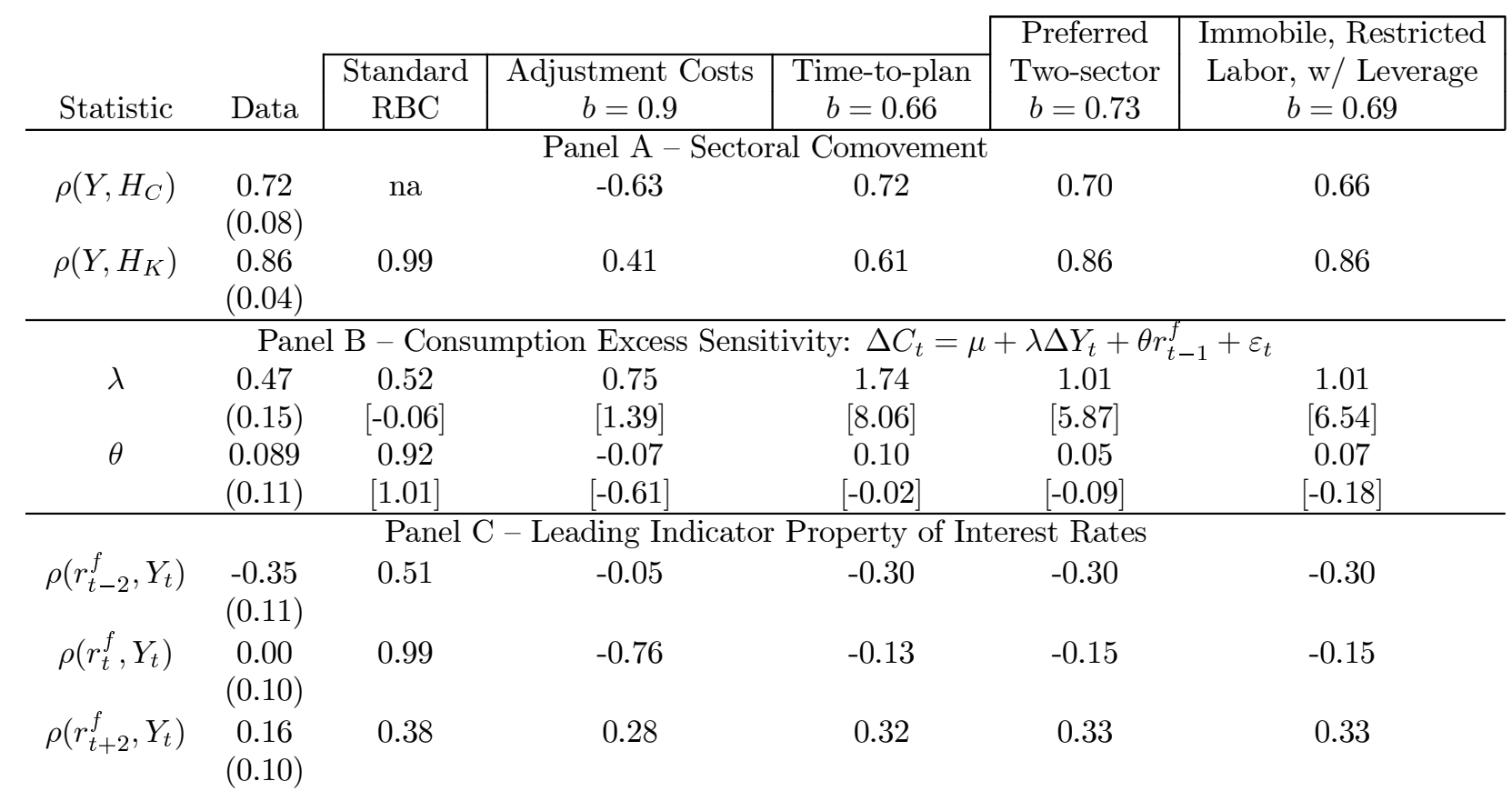

Notes to Table 6: (i) For explanation of model names, see 'Abbreviated names' in Table 1 ; (ii) $\sigma_{x}$ denotes the standard deviation of variable $x, \rho(x, y)$ denotes the correlation between $x$ and variable $y$, where $x$ and $y$ are logged and HP filtered prior to analysis; (iii) The "Data" column for Panels A and C contains estimates (standard errors in parenthesis) based on the sample period 1964:1-1988:2. See note (iii), Table 3, for a description of the output data and the estimation procedure used. The sectoral hours and interest rate data are from DRI Basic Economics Database. For the consumption sector we used two alternative measures: an index of hours worked in the service sector (DRI series LWHPX) and an index of hours worked in the nondurable manufacturing sector (LWHNX). The estimate for the consumption sector hours worked correlation is based on LWHPX. The analogous point estimate (standard error) based on LWHNX is $0.83(0.05)$. The estimate for the investment sector hours worked is based on hours worked in the durable manufacturing sector (LWHDX.) The real interest rate at date $t$ for the statistics in Panel $\mathrm{C}$ is measured as the nominal Federal Funds rate (FYFF) at date $t$ less the realized inflation rate between dates $t$ and $t+1$. The price for calculating the inflation rate is the deflator on nondurable and services consumption, $(\mathrm{GCN}+\mathrm{GCS}) /(\mathrm{GCNQF}+\mathrm{GCSQF})$, where the mnemonics are taken from the DRI database. Estimates for $\lambda$ and $\theta$ in Panel B are taken from Campbell and Mankiw (1989); (iv) Entries in square brackets in Panel B are the probability limits discussed in the text. Unbracketed results for the model in all three panels are based on 500 replications of sample size 200 . The model and data instrumental variables estimates for $\lambda$ and $\theta$ in Panel $\mathrm{B}$ are based on the instrument list $\left\{\Delta c_{t-2}, \Delta c_{t-3}, \Delta c_{t-4}, r_{t-3}^{f}, r_{t-4}^{f}, r_{t-5}^{f}\right\}$, where $\Delta x_{t}=\ln x_{t}-\ln x_{t-1}$; (vi) 'na' abbreviates the phrase 'not applicable.' 
Figure 1: Impulse response functions implied by various models

\section{A: Output}

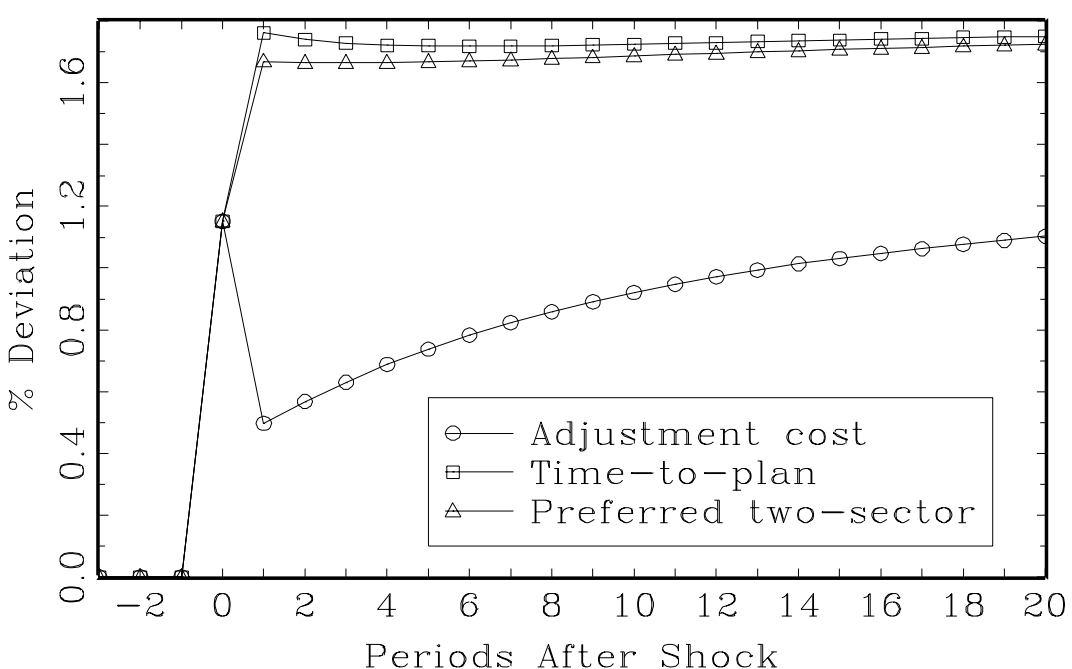

C: Consumption

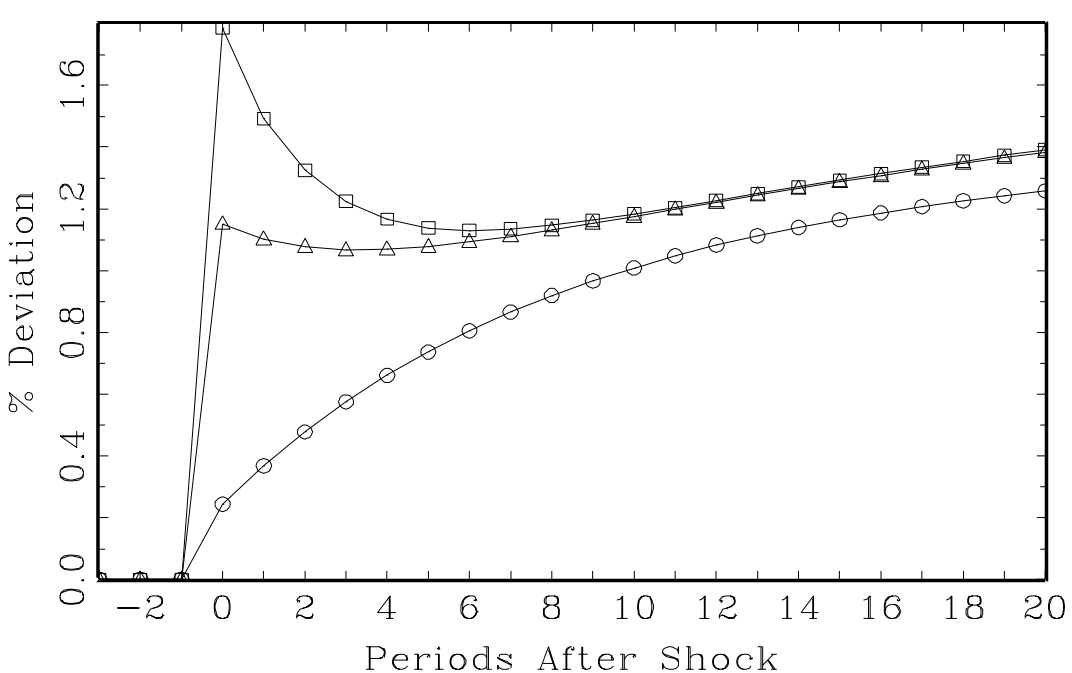

B: Labor

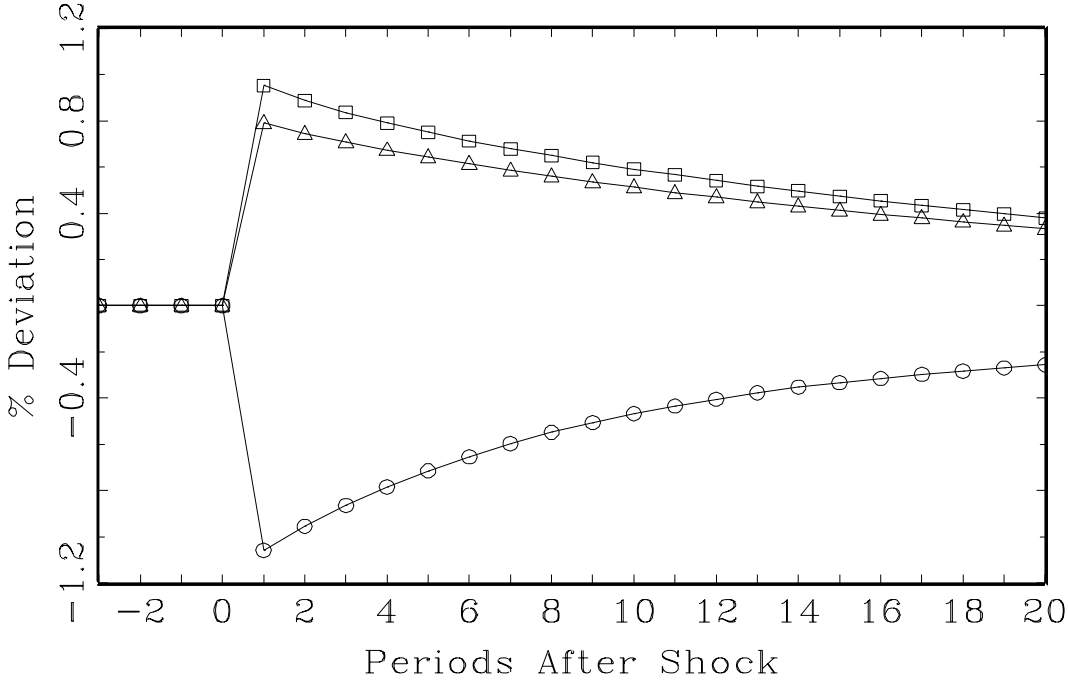

D: Investment

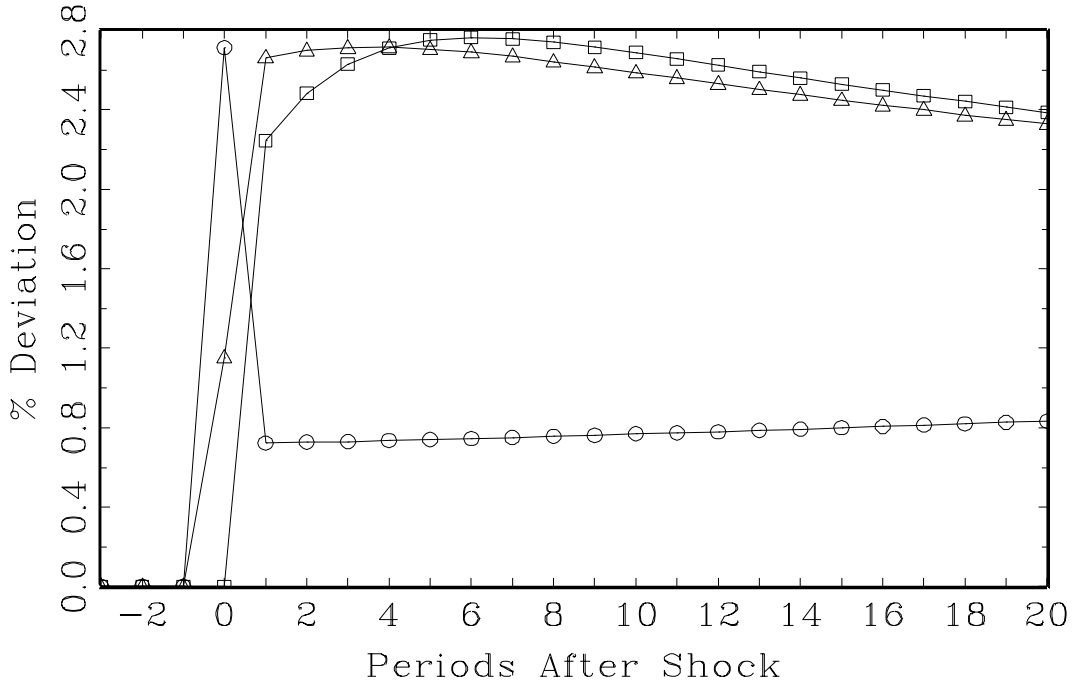


Figure 2: Impulse response functions showing the importance of the 'Immobile Labor' assumption for generating sectoral labor co-movement in the two-sector models

\section{A: Labor Employed in the Consumption Sector}

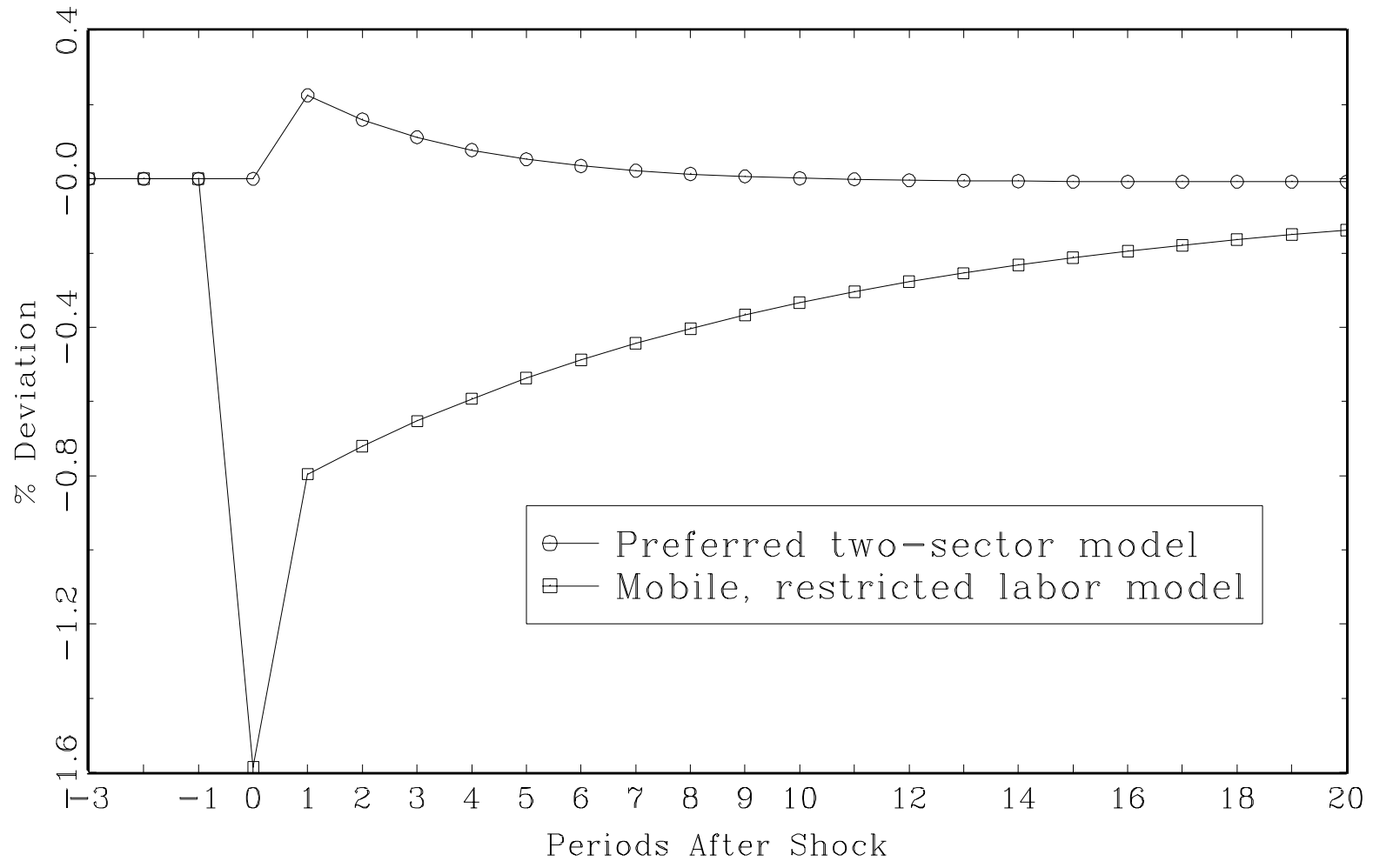

B: Labor Employed in the Investment Sector

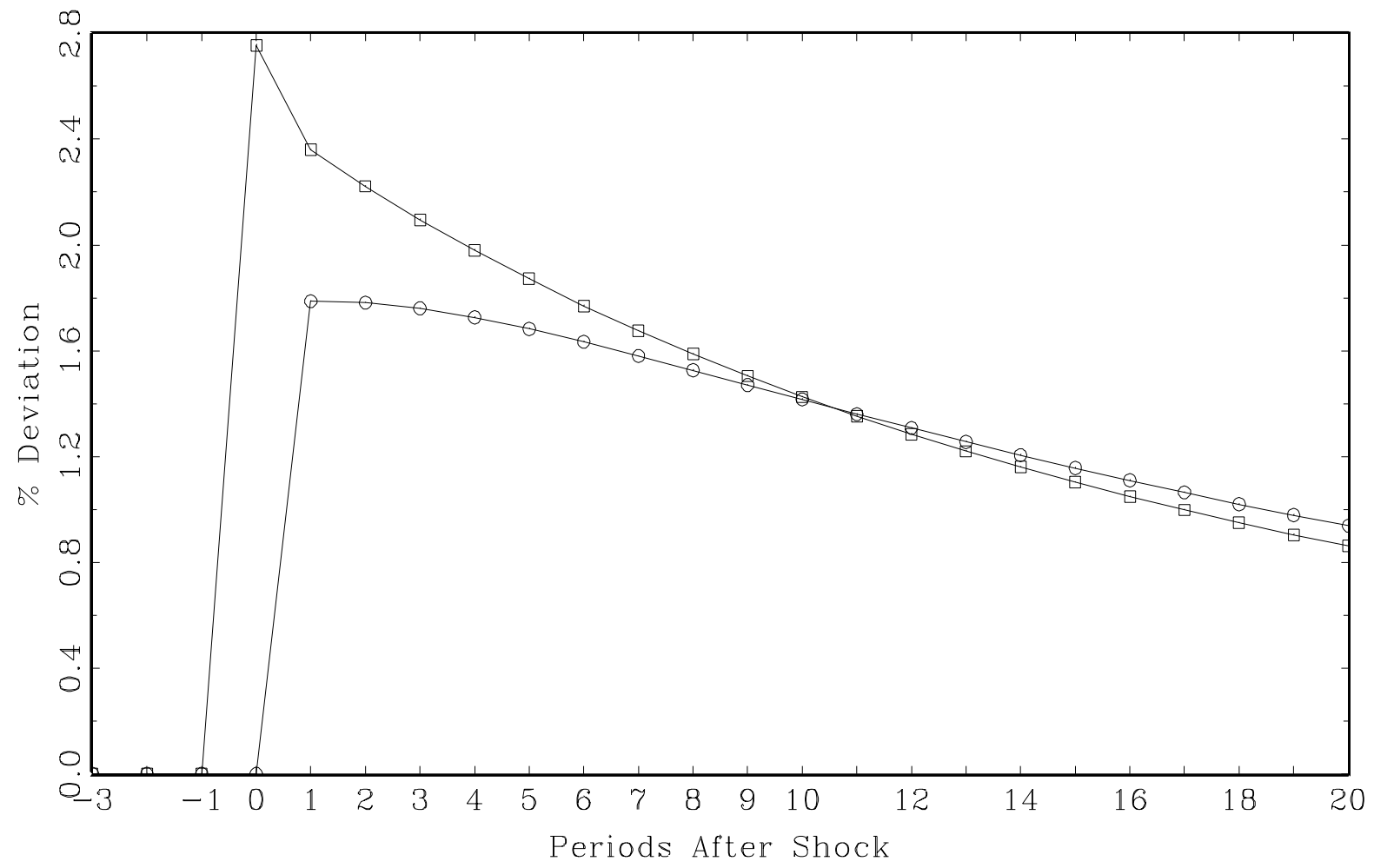

